\title{
The Ventral Midline Thalamus Mediates Hippocampal Spatial Information Processes upon Spatial Cue Changes
}

\author{
Dahee Jung, ${ }^{1,2,3}$ Yeowool Huh, ${ }^{3,4}$ and Jeiwon Cho ${ }^{3,4}$ \\ ${ }^{1}$ Center for Neuroscience, Korea Institute of Science and Technology, Seongbuk-gu, Seoul 02792, Korea, ${ }^{2}$ Neuroscience Program, Korea University of \\ Science and Technology, Daejeon 34113, Korea, ${ }^{3}$ Translational Brain Research Center, Catholic Kwandong University International St. Mary's Hospital, \\ Incheon 22711, Korea, and ${ }^{4}$ Department of Medical Science, College of Medicine, Catholic Kwandong University, Gangneung-si, Gangwon-do 25601, Korea
}

The ventral midline thalamus, consisting of the reuniens and rhomboid nuclei ( $\mathrm{RE} / \mathrm{Rh})$, is a thalamic structure interconnected with the limbic systems including the hippocampus. Recently, many studies have revealed that this structure plays distinctive roles in spatial learning and memory in collaboration with hippocampal functions. However, what aspects of spatial information process are influenced by the $\mathrm{RE} / \mathrm{Rh}$ is not clearly known. To elucidate the roles of $\mathrm{RE} / \mathrm{Rh}$ in spatial information processing and its effects on hippocampal activity, specifically with the manipulation of spatial contents, we measured hippocampal-dependent spatial memory performance and hippocampal place cell activities after RE/Rh lesion using male C57BL/6J $\times 129 / \mathrm{SvJae}$ hybrid mice. We found that the lesion altered the behavioral aptitude in recognizing locational changes of an object. Furthermore, CA1 place cells in the lesion group showed different spatial representation patterns in recognizing the environment with cue locational changes compared with the control group. Interestingly, the patterns of CA1 place cells in recognizing the same environment previously visited were not disrupted in the lesion group compared with the control group. These findings demonstrate that the ventral midline thalamus (RE/Rh) is important in recognizing the spatial relationships, especially when spatial rearrangement of cue position was introduced.

Key words: hippocampus; nucleus reuniens; object location; place cells; spatial information; ventral midline thalamus

Significance Statement

The ventral midline thalamic nuclei (reuniens and rhomboid) interact with the hippocampus to influence various cognitive functions requiring spatial memories, yet what aspects of spatial information process are influenced by these nuclei is not clearly known. Here, we reveal that these nuclei play a crucial role in modulating hippocampal properties only with locational rearrangement of cues, not with the familiar arrangement. These nuclei are distinctively involved in cue-dependent spatial information processes of CA1 place cells. In particular, we suggest that these nuclei modulate spatial information processing on discrete components, especially when the spatial cue relationship is modified.

\section{Introduction}

The capability of recognizing locations of spatial cues and their spatial relationships is crucial for forming episodic memories in daily life (Cohen et al., 1997; Brown and Aggleton, 2001; Dere et al., 2005; Davis et al., 2013; Brewin, 2014). Dysfunction of this

\footnotetext{
Received Aug. 20, 2018; revised Dec. 18, 2018; accepted Jan. 11, 2019.

Author contributions: D.J. and J.C. wrote the first draft of the paper; D.J., Y.H., and J.C. edited the paper; D.J. and J.C. designed research; D.J. performed research; D.J. and J.C. contributed unpublished reagents/analytic tools; D.J., Y.H., and J.C. analyzed data; D.J., Y.H., and J.C. wrote the paper.

This work was supported by the Ministry of Science and ICT through the National Research Foundation of Korea Brain Science Research Program (Grant NRF-2015M3C7A1028392 to J.C. and Grant NRF-2018M3C7A1024736 to Y.H.).

The authors declare no competing financial interests.

Correspondence should be addressed to Yeowool Huh at huh06@cku.ac.kr or Jeiwon Cho at jelectro21@gmail.com.

https://doi.org/10.1523/JNEUROSCI.2127-18.2019

Copyright $\odot 2019$ the authors $\quad 0270-6474 / 19 / 392276-15 \$ 15.00 / 0$
}

ability can induce severe cognitive deficits, as observed in human patients and disease animal models (Dere et al., 2005; Davis et al., 2013; Brewin, 2014), and the hippocampus is a well studied candidate that processes spatial cue information in episodic memory processes (Scoville and Milner, 1957; Brown and Aggleton, 2001; Langston and Wood, 2010). Individual pyramidal neurons in the hippocampus have distinctively preferred locations to fire, which are susceptible to characteristics of spatial cues in a given environment (O'Keefe, 1979; Muller and Kubie, 1987; Calton et al., 2003; Knierim and Hamilton, 2011; Park et al., 2015) and controlled by various spatial components such as distal landmarks and local cues (Lee et al., 2004; Knierim and Hamilton, 2011; Neunuebel et al., 2013). Despite the wealth of investigations on how different spatial configurations are interpreted through the location-dependent firing of hippocampal place cells, the pathways for distinctive components composing the spatial processing system have not been clearly revealed because it is 
complicatedly influenced by interactive brain systems such as memory, perceptual, motivational systems, and many more (Lee et al., 2004; Neunuebel et al., 2013). For example, stress on animals is known to decline hippocampal functions and shifts the navigational strategy from a spatial to a local-stimulus-based response strategy, which involves a brain circuitry composed of the striatum, $\mathrm{mPFC}$, and other brain regions (Kim et al., 2007; Park et al., 2015) rather than solely depending on the hippocampus. Therefore, attempts to interpret the spatial information processing of the hippocampus at the circuit level are crucial for in-depth understanding of the spatial information processing.

The ventral midline thalamus, including the reuniens and rhomboid nuclei (RE/Rh), is often described as the limbic thalamus due to its anatomical connections with the limbic system and related brain structures (Vertes et al., 2006, 2007; Cassel et al., 2013; Vertes et al., 2015). Furthermore, animal studies have shown that manipulating activities of the RE/Rh produces cognitive impairments comparable to medial temporal lobe malfunctions (Vertes et al., 2007, 2015). Investigations on circuitry functions of $\mathrm{RE} / \mathrm{Rh}$ have been challenged due to its intermingled and widespread projections to diverse cortical and subcortical brain regions. However, several studies have started to pay attention to the anatomical connections between the RE/Rh and CA1. Furthermore, the unique anatomical feature that relatively large percentages of $\mathrm{RE} / \mathrm{Rh}$ neurons reciprocally project to both CA1 and $\mathrm{mPFC}$ has attracted more attention because this reciprocal connectivity was shown to be involved in complex cognitive functions such as goal-directed path and fear extinction (Vertes et al., 2007; Cassel et al., 2013; Ito et al., 2015; Vertes et al., 2015; Salay et al., 2018), spatial learning and memory (Hallock et al., 2013; Barker and Warburton, 2018; Cholvin et al., 2018), and spatial working memory and associative recognition memory (Duan et al., 2015; Hallock et al., 2016; Barker and Warburton, 2018). Although substantial evidence in anatomical and behavioral studies suggests that the RE/Rh is functionally linked to the hippocampal CA1 region, no study has investigated how the $\mathrm{RE} / \mathrm{Rh}$ modulates spatial representation of CA1 place cells when the preexisting cues with different subsets of spatial configuration change their positions.

Here, we investigated the roles of RE/Rh on processing spatial components in relation to the hippocampal CA1 region via analyzing behavioral performances and hippocampal place cell activities after RE/Rh lesion along with the manipulation of spatial cue locations.

\section{Materials and Methods}

Animals

First generations of male hybrid mice of C57BL/6J $\times 129 /$ SvJae at age $>8$ weeks were used in all experiments. Mice were maintained under an alternating $12 \mathrm{~h}$ light/dark cycle (lights on at 8:00 A.M.) in their home cages and had ad libitum access to water and food. All experiments and procedures followed guidelines set and approved by Institutional Animal Care and Use Committee of the Korea Institute of Science and Technology (Approval \#2015019). The handling procedure was conducted for 1 week before all types of behavioral experiments for mice to acclimate to the experimenter and the experimental environments.

\section{Stereotaxic surgery}

Mice were anesthetized with Zoletil $(30 \mathrm{mg} / \mathrm{kg})$ and head-fixed to a stereotaxic instrument (David Kopf Instruments) for electrolytic lesion and microdrive implantation. The method of electrolytic lesion was adopted from a previous study (Corbit and Balleine, 2000). For behavioral experiments, electrolytic lesions were made in the RE/Rh by passing anode currents $(0.7 \mathrm{~mA}$ for $7 \mathrm{~s}$ ) through electrode tips targeting the RE/Rh (AP: $0.8 \mathrm{~mm}$, ML: $0.6 \mathrm{~mm}, \mathrm{DV}: 4.1 \mathrm{~mm}$ at angle of $12^{\circ}$ ). For the Sham group, littermates underwent the same procedure without the passage of current. For single-unit recording, the electrolytic lesion-making procedure was followed by microdrive implantation, targeting hippocampal CA1 neurons at coordinates of $1.9 \mathrm{~mm}$ ventral and $1.4 \mathrm{~mm}$ lateral to bregma and $1.2 \mathrm{~mm}$ depth from brain surface. The microdrive consisted of four tetrodes that were made up of four nichrome wires $(12.5 \mu \mathrm{m}$; Kanthal Precision Technology). It was gold-plated to reach the impedance of $0.2-0.5 \mathrm{M} \Omega$ measured at $1 \mathrm{kHz}$. All mice that underwent stereotaxic surgery were given 1 week of recovery and handled for 1 week before behavioral and recording experiments.

\section{Histology}

To verify whether the electrolytic lesion had been made in the target regions, mice used for all experiments were anesthetized with $2 \%$ Avertin after the completion of experiments. Then, only for those mice used in single-unit recording experiments were extra microcurrents $(20 \mu \mathrm{A}$ for $10 \mathrm{~s}$ ) additionally passed through the tetrode tips to verify the recording sites. The mice were perfused transcardially with saline followed by $10 \%$ formalin for brain removal. Extracted brains were fixed in $10 \%$ formalin for $1 \mathrm{~d}$ and then dehydrated in 30\% sucrose solution for $2 \mathrm{~d}$ before sectioning. Coronal sections (50 $\mu \mathrm{m}$ thick) were then collected on glass slides and stained with Cresylviolet (Sigma-Aldrich). Lesion and recording sites in target brain regions were then confirmed by examining under a light microscope.

\section{Experimental design}

$Y$-maze task. A Y-shaped Plexiglas was used for assessing working memory and willingness to explore new environments as described in a previous work (Sham, $n=9$; RE/Rh, $n=9$ ) (Jung et al., 2016). The apparatus consisted of three identical arms $(36 \mathrm{~cm}$ in length, $12 \mathrm{~cm}$ in height, $3 \mathrm{~cm}$ in width). Each mouse was placed in this apparatus and allowed to freely explore the arms for $8 \mathrm{~min}$. Sequences of the individual arm's entries were recorded and analyzed to calculate the success in alternation, which was defined as the three consecutive entries of the three different arms.

$$
\text { Alternation success }(\%)=\frac{\# \text { of Success in Alternation }}{\# \text { of total entries }-2} \times 100
$$

Open-field task. An open-field task was performed in a white Plexiglas box $(40 \mathrm{~cm} \times 40 \mathrm{~cm} \times 40 \mathrm{~cm})$ to examine locomotor activity as described previously (Jung et al., 2016). The behavioral room condition was maintained the same throughout the whole experiment with white noise sound and lighting $\left(80 \mathrm{~dB}, 20\right.$ lux at $24^{\circ} \mathrm{C}$ ). Mice (Sham, $n=9 ; \mathrm{RE} / \mathrm{Rh}$, $n=9$ ) were placed in the room for $30 \mathrm{~min}$ before the task in the testing room for acclimatization to the environment. For the experiment, each mouse was located in the box and monitored for $30 \mathrm{~min}$ through behavioral counting program (Noldus Information Technology). As a measurement of locomotor activity and anxiety level, we calculated walking distance in centimeters and percentage of time in the central area of the box.

Object location recognition task. In the object location recognition task, each mouse (Sham, $n=8 ; \mathrm{RE} / \mathrm{Rh}, n=9$ ) was introduced to a gray acryl box $(30 \mathrm{~cm} \times 30 \mathrm{~cm} \times 40 \mathrm{~cm})$ with stripes and a silver card on each side as intended spatial cues for $10 \mathrm{~min}$ for $2 \mathrm{~d}$ before a training and test day. On the next day, during a training phase, each mouse entered into the acryl box with identical two objects and freely explored for $10 \mathrm{~min}$. One hour later, during a test phase, the mouse reentered into the same box to freely explore the same objects for $5 \mathrm{~min}$. One of the two identical objects was positioned at the different location compared with the previous phase. The object that stayed at the same position and the other that was switched to different positions were referred as a stationary object (Object $\mathrm{A}$ in the training phase) and a displaced object (Object B in the training phase), respectively. For further analysis, the test phase was divided in half (2.5 min each) and referred to as test phase I $(0-2.5 \mathrm{~min})$ and test phase II $(2.5-5 \mathrm{~min})$. The moments in which mice headed directly toward each object within $<2 \mathrm{~cm}$ distance were considered as exploration and were calculated as a percentage relative to the total exploration time.

The discrimination index (DI) was measured using the following equation: 
Discrimination Index (DI)

Time spent in displaed object - Time spent in stationary object Time spent in displaed object + Time spent in stationary object

Extracellular recording in freely moving mice. A recording room was equipped with white noise and dim light with visual cue cards attached to surrounding curtain, acting as spatial distal cues. Recording was conducted in a black acrylic cylinder (30 cm in diameter, $12.7 \mathrm{~cm}$ in height) with a white paper attached inside acting as a local visual cue. Recording procession consisted of three sessions: session A (SA), SB (SB), and session $\mathrm{A}^{\prime}\left(\mathrm{SA}^{\prime}\right)$, for 20 min per session spaced with $\sim 5 \mathrm{~min}$ intervals. The recording cylinder with the cue card was rotated $90^{\circ}$ counterclockwise in SB after completion of SA and consequently re-rotated $90^{\circ}$ clockwise $\left(270^{\circ}\right.$ counterclockwise) in the following session, $\mathrm{A}^{\prime}$. Therefore, comparisons between $\mathrm{SA}$ versus $\mathrm{SA}^{\prime}$ were analyzed for the same spatial circumstance, whereas comparisons between $\mathrm{SA}$ versus $\mathrm{SB}$ (or SB vs $\mathrm{SA}^{\prime}$ ) were analyzed to observe the impact of the manipulation in spatial cue arrangement in depth.

Recording signals from freely moving mice were filtered within $600 \mathrm{~Hz}$ to $6 \mathrm{kHz}$, amplified $1000 \times$, and then digitized $(30.3 \mathrm{kHz})$ using the Cheetah system (Neuralynx) and isolated into single units using Spikesort3D program (Neuralynx). Single-unit recording was conducted to target CA1 place neurons in two groups: the Sham group ( $n=75$ from 7 mice) and the RE/Rh group with electrolytic lesions in RE/Rh nuclei ( $n=54$ from 5 mice). Only single-unit data that met the criteria of hippocampal pyramidal neurons (mean firing rate $>0.1 \mathrm{~Hz}$ in at least one session, refractory period $>1 \mathrm{~ms}$, presence of burst spikes) were used for analyses. Here, burst was defined as a bundle of $>2$ spikes with $15 \mathrm{~ms}$ or lower interspike intervals with progressively decreasing amplitudes. Position data obtained from LED lights mounted on an animals' heads were constructed in pixel units $(1 \times 1 \mathrm{~cm})$ for firing rate map. Pixels that each mouse visited for $>1 \mathrm{~s}$ were used to compose a place rate map, represented as firing rates in each pixel. A place field was defined as a group of pixels for which the firing rate exceeded average the firing rate by $>2$ SDs. Additional parameters of place rate map such as in-field rate, out-field rate, and coherence were calculated as described previously (Kim et al., 2012; Jung et al., 2016).

In similarity analyses to quantify likeness of place rate maps between sessions, pixel-by-pixel cross-correlation from two sessions was calculated and transformed into Fisher's $Z$ score. The place rate map in the later session was then rotated clockwise by from $0^{\circ}$ to $360^{\circ}$ in $5^{\circ}$ intervals to recalculate the likeness with the former session at each rotated angle, which was termed rotational similarity (Knierim, 2002; Lee et al., 2004). Similarity score was a correlation value between two original place rate maps, and local cue similarity was a correlation value between two sessions, the latter of which was rotated $\left(90^{\circ}\right.$ clockwise for SA-SB comparison or $90^{\circ}$ counterclockwise for SB-SA' comparison) to measure the place cells response to the rotated local cue. The degree of rotated angle that led to finest matching place maps was referred as rotation angle and the highest correlation value was referred as the maximum similarity. Categories of neuronal responses toward cue manipulation (cue dependency) were classified into three groups according to rotation angle: stay, rotated, and remapped.

\section{Experimental design and statistical analysis}

The overall behavioral design is described in Figure 1B. Different mice were assigned into each set of behavioral experiment. For group comparison in the open-field and Y-maze tasks, we performed unpaired Student's $t$ test. In the object recognition task, we used paired Student's $t$ test to compare exploration time on stationary and displaced objects of individual mouse, as well as unpaired Student's $t$ test for group comparisons of the DI.

The experimental design to examine place cell properties is presented in Figure 3, A-C. To compare the groups across the sessions, we performed two-way repeated ANOVAs for group comparisons and LSD as post hoc analyses for comparison within and between groups to assess $\mathrm{RE} / \mathrm{Rh}$ lesion effects on firing rates, spatial coherence, and field size. Then, to compare place maps between two sessions from each place cell, we calculated the cross-correlation values between the corresponding firing rates in pixels. Using these data, Watson-Williams test values were calculated to compare rotational similarity distributions between groups. Vector properties in circular statistics and $\mathrm{chi}^{2}$ test were used to describe rotation angle and cue dependency categories, respectively.

All data were expressed as mean \pm SEM throughout and statistical analyses were used in PASW Statistics (version 20) or MATLAB (The MathWorks). For the similarity analyses between sessions, circular statistics were conducted using the MATLAB circular statistics toolbox.

\section{Results}

\section{$\mathrm{RE} / \mathrm{Rh}$ lesion does not affect general behaviors}

The location of RE/Rh lesion was confirmed by histology, as shown in Figure $1 A$, and only the data with a precise lesion in $\mathrm{RE} / \mathrm{Rh}$ were included in the analyses. Behavioral experiments were conducted to investigate its roles in hippocampal-dependent learning and memory (Fig. $1 B$ ). First, the open-field and Y-maze spontaneous alternation tasks were used to assess the possibility that the RE/Rh lesion had affected general behaviors, which could consequently influence the performance of spatial memory tasks (Fig. 1C-F). Results showed that general locomotion was not affected by the RE/Rh lesion because the total distance moved was not significantly different in the open-field task (Fig. $1 C$; Sham $=74326.9 \pm 8302 \mathrm{~cm}, \mathrm{RE} / \mathrm{Rh}=72045.12 \pm$ $4074.62 \mathrm{~cm}, p=0.80$, unpaired Student's $t$ test). Second, the anxiety-like behavior of the RE/Rh group was also not significantly different compared with the Sham group, as shown by the similar percentages of dwelling time in the central area of the open-field arena (Fig. 1D; Sham $=16.9 \pm 2.89 \%, \mathrm{RE} / \mathrm{Rh}=$ $12.1 \pm 1.79 \%, p=0.17$, unpaired Student's $t$ test). Third, the results of the continuous spontaneous alternation task indicate that the RE/Rh lesion did not alter motivation to explore arms in a maze, as shown by the number of entries (Fig. $1 E$; Sham $=37 \pm$ 2.7, $\mathrm{RE} / \mathrm{Rh}=34 \pm 2, p=0.56$, unpaired Student's $t$ test). In addition, the $\mathrm{RE} / \mathrm{Rh}$ lesion did not impair working memory and willingness to explore new environments, as shown by the percentage of success in alternation (Fig. $1 F$; Sham $=69.53 \pm 2.55 \%$, $\mathrm{RE} / \mathrm{Rh}=67.45 \pm 2.33 \%, p=0.30$, unpaired Student's $t$ test). These results indicate that the RE/Rh lesion did not lead to abnormality in general behaviors.

\section{$\mathrm{RE} / \mathrm{Rh}$ lesion affects performance in object location recognition}

An object location recognition task assesses the capabilities to distinguish the locational change of identical objects compared with what animals have formerly experienced. As illustrated in Figure $2 A$, it measures mice's preference to an object in a new position (displaced object) over another object in the same position (stationary object) during the test phase by using the locational information from the former training phase. During the training phase neither group showed statistical preferences over the identical objects (Sham, Object A $=49 \pm 2.9 \%$, Object B $=51 \pm$ $2.9 \%, p=0.66$; RE/Rh, Object $\mathrm{A}=52 \pm 3.1 \%$, Object B $=48 \pm$ $3.1 \%, p=0.54$, paired Student's $t$ test) as shown in Figure $2 B$. The test phase $(5 \mathrm{~min})$ was divided into test phase I ( $0-2.5 \mathrm{~min})$ and test phase II (2.5-5 $\mathrm{min}$ ) to investigate how exposure time influences preference because animals tend to have strong novelty preference during the initial exposure, which gradually decreases over time. In test phase I (Fig. 2C), preference toward the displaced object was observed in both the Sham group (displaced object $=73 \pm 5.9 \%$, stationary object $=27 \pm 5.9 \%, p=0.006$, paired Student's $t$ test) and the RE/Rh group (displaced object $=$ $67 \pm 3.2 \%$, stationary object $=33 \pm 3.2 \%, p<0.001$, paired Student's $t$ test). However, during test phase II, the Sham group 


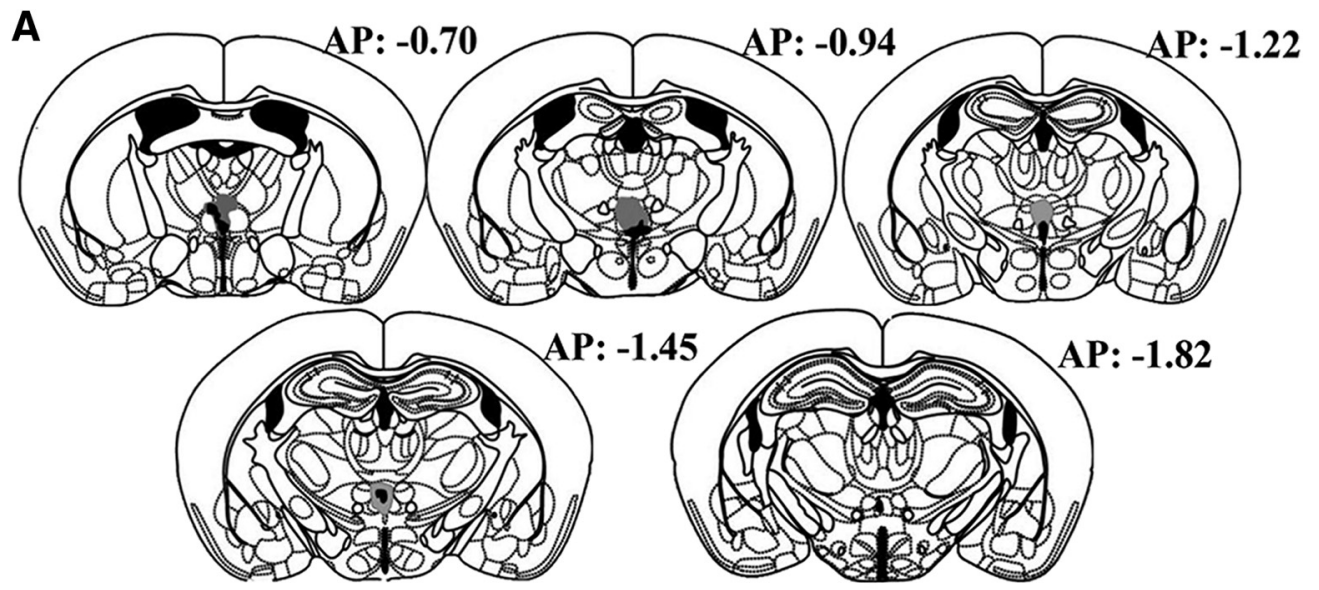

B

\section{Behavioral Tasks}

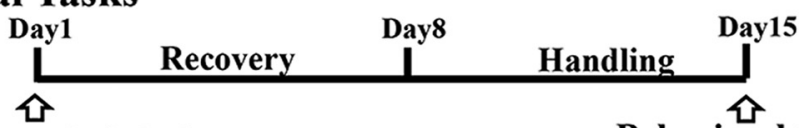

Electrolytic lesion

1. $\operatorname{Sham}(\mathrm{N}=9) / \mathrm{RE} / \mathrm{Rh}(\mathrm{N}=9)$

2. $\operatorname{Sham}(\mathrm{N}=9) / \mathrm{RE} / \mathrm{Rh}(\mathrm{N}=9)$

3. $\operatorname{Sham}(\mathrm{N}=8) / \mathrm{RE} / \mathrm{Rh}(\mathrm{N}=9)$

C

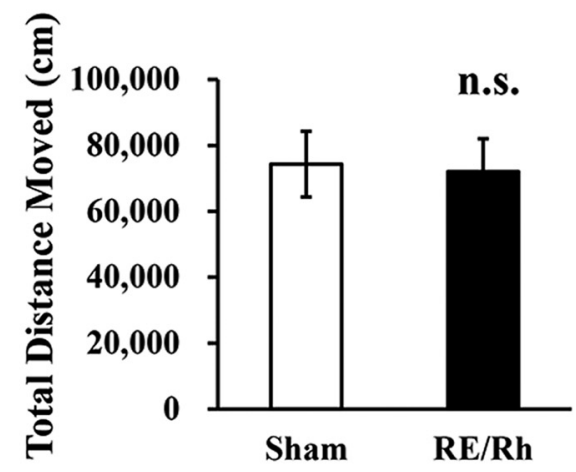

E

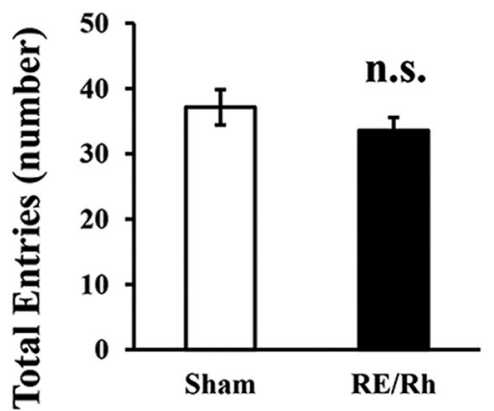

Behavioral tasks start

1. Open field task

2. Y-Maze task

3. Object location recognition task

D

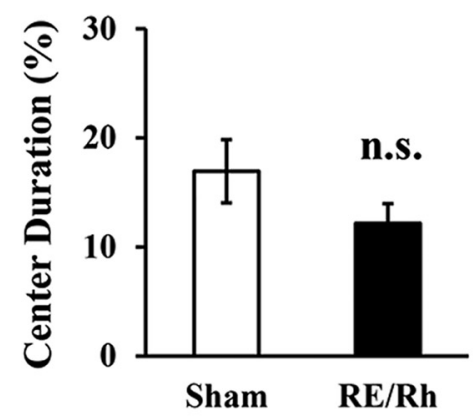

F

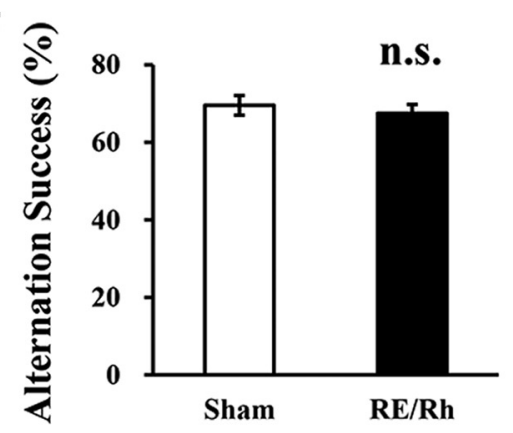

Figure 1. A, Schematic features of electrolytic lesions in the RE/Rh regions. Coronal sections show outlines of the mildly lesioned areas (gray) and extensively lesioned area (black) at different AP coordinates. $\boldsymbol{B}$, Schedules for investigating the roles of RE/Rh on the behavioral tasks. $C, D, 0$ pen-field test comparing locomotor activity between groups. The schematic draws at each coordinate were adapted from the pictures (Paxinos and Franklin, 2004). C, Total distance moved in centimeters indicates that both groups showed similar locomotor activity. $\boldsymbol{D}$, Percentage of time in the center demonstrates that both groups had a similar degree of anxiety-like behavior. $\boldsymbol{E}, \boldsymbol{F}, Y$-maze task to investigate working memory. $\boldsymbol{E}$, Number of total entries to arms showing no group differences. $\boldsymbol{F}$, Percentage of success in alternation showing no group differences. Data were analyzed with unpaired two-tailed $t$ test.

still showed a preference for the displaced object (displaced object $=70 \pm 5.2 \%$, stationary object $=30 \pm 5.2 \%, p=0.006$, paired Student's $t$ test), whereas the RE/Rh group showed no preference (displaced object $=54 \pm 5.2 \%$, stationary object $=$ $46 \pm 5.2 \%, p=0.490$, paired Student's $t$ test). The difference in exploration time of each object between groups in the test phase also shows a similar trend (Table 1). Running speeds of the two groups were measured during the test phases (phase I and II) to investigate whether a difference between groups may have influenced behavioral patterns during novelty detection. There were no differences in the running speed between groups during phase $\mathrm{I}(\mathrm{Sham}=4.8 \pm 0.40 \mathrm{~cm} / \mathrm{s}, \mathrm{RE} / \mathrm{Rh}=4.6 \pm 0.37 \mathrm{~cm} / \mathrm{s}, p=0.73$, unpaired $t$ test) or during phase II (Sham $=4.0 \pm 0.23 \mathrm{~cm} / \mathrm{s}$, $\mathrm{RE} / \mathrm{Rh}=4.3 \pm 0.21 \mathrm{~cm} / \mathrm{s}, p=0.31$, unpaired $t$ test). In short, the 
A

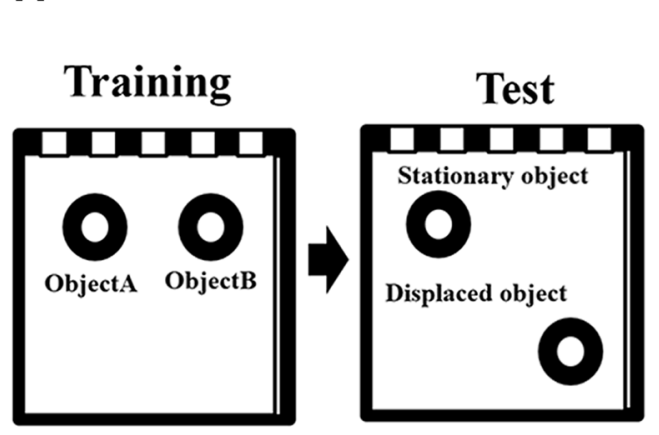

C
B Training

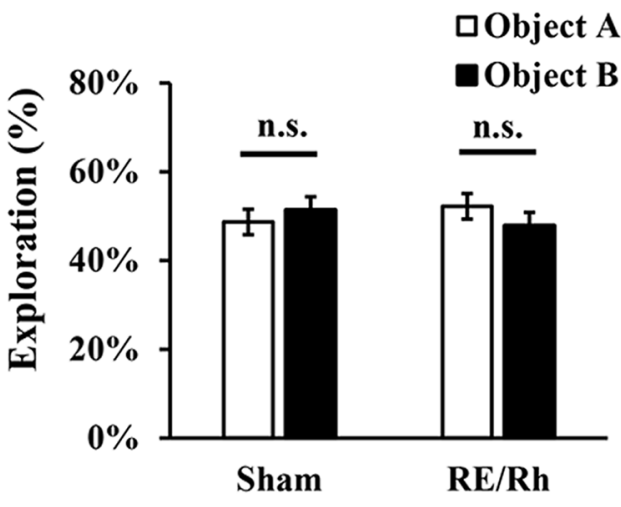

口Displaced object

- Stationary object

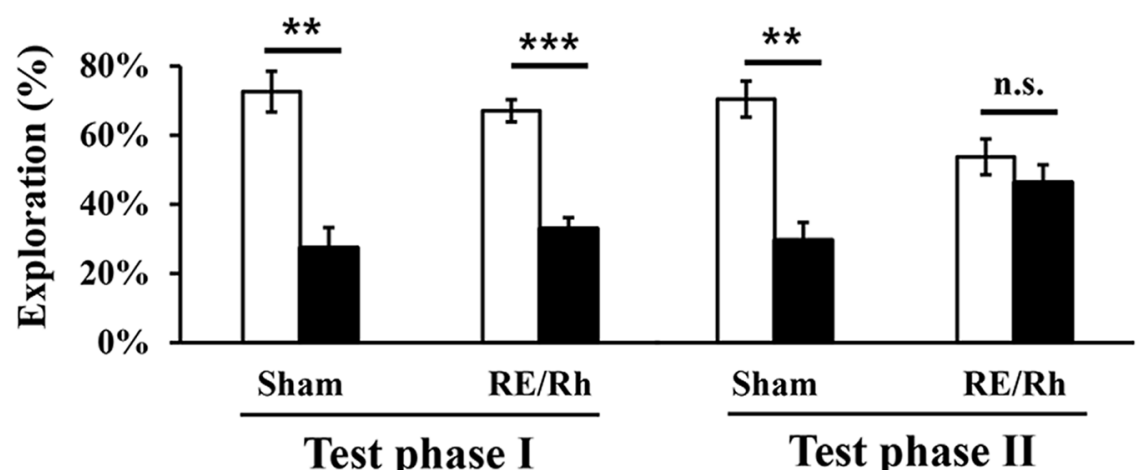

D

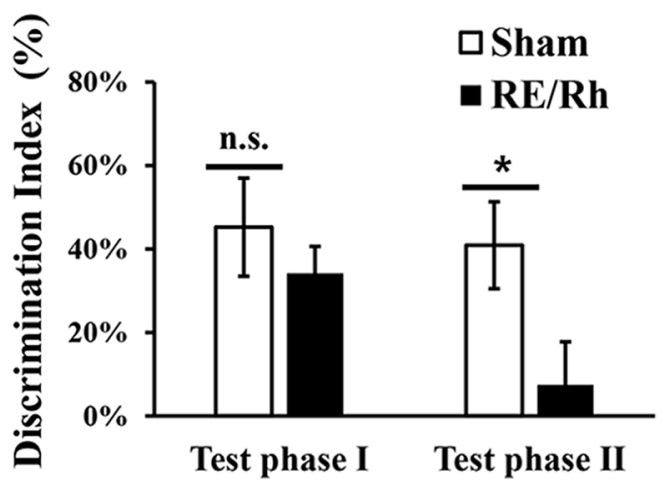

E

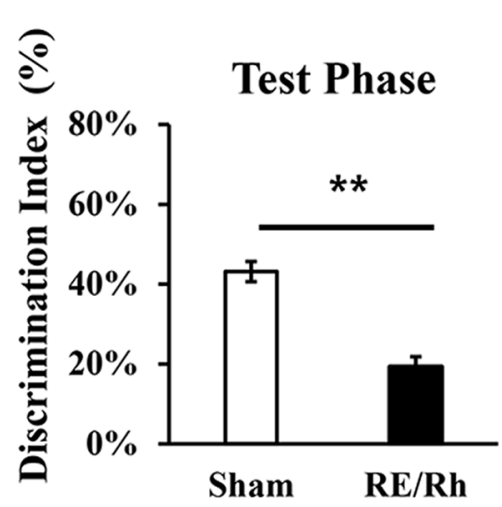

Figure 2. Object location test. A, Diagram of the task consisting of training and test phases. B, During a training phase, neither group showed preference for the objects (aired two-tailed $t$ test). C, During test phase I, both groups showed preference toward the displaced object over the stationary object; however, only the Sham group showed preference during test phase II (aired two-tailed $t$ test). $\boldsymbol{D}, \mathrm{Dl}$ showing that the reduced ability of the RE/Rh group to recognize changes only occurs in test phase II (unpaired two-tailed $t$ test). $\boldsymbol{E}$, During the entire test phase, the DI shows group differences (unpaired two-tailed $t$ test; ${ }^{*} p<0.05,{ }^{* *} p<0.01,{ }^{* * *} p<0.001$ ).

Table 1. Exploration time during the test phase of an object location recognition task (seconds)

\begin{tabular}{|c|c|c|c|c|}
\hline & \multicolumn{2}{|l|}{ Test phase I } & \multicolumn{2}{|l|}{ Test phase II } \\
\hline & Sham & $\mathrm{RE} / \mathrm{Rh}$ & Sham & $\mathrm{RE} / \mathrm{Rh}$ \\
\hline Total & $17.2 \pm 2.56 \mathrm{~s}$ & $14.2 \pm 2.62 \mathrm{~s}$ & $21.0 \pm 4.28 \mathrm{~s}$ & $19.1 \pm 3.42 \mathrm{~s}$ \\
\hline Displaced object & $11.7 \pm 1.16 \mathrm{~s}$ & $9.4 \pm 1.73 \mathrm{~s}$ & $15.1 \pm 3.34 \mathrm{~s}$ & $10.7 \pm 2.36$ \\
\hline Stationary object & $5.5 \pm 1.83 \mathrm{~s}$ & $4.8 \pm 1.12 \mathrm{~s}$ & $5.9 \pm 1.45 \mathrm{~s}$ & $8.5 \pm 1.65$ \\
\hline $\begin{array}{l}\text { Displace vs stationary } \\
\quad \text { (paired } t \text { test value) }\end{array}$ & $p=0.008$ & $p=0.007$ & $p=0.014$ & $p=0.346$ \\
\hline
\end{tabular}

Preference to displaced/stationary objects of each group during test phase I and test phase II are separately described. The exploration time on displaced object versus stationary object were statistically compared using paired Student's t test.
$\mathrm{RE} / \mathrm{Rh}$ lesion did not affect running speed and would not have affected the result of either test phase I or test phase II during the object location recognition task. The DI indicates that there were group difference in test phase II (Sham $=41 \pm 10.4 \%, \mathrm{RE} / \mathrm{Rh}=$ $7 \pm 10.3 ; p=0.038$, unpaired Student's $t$ test), but not in test phase I (Sham $=45 \pm 11.8 \%, \mathrm{RE} / \mathrm{Rh}=34 \pm 6.4 ; p=0.410$, unpaired Student's $t$ test) (Fig. 2D). Overall, during the entire test phase ( $5 \mathrm{~min}$ ), the $\mathrm{RE} / \mathrm{Rh}$ lesion diminished the ability to recognize changes on the location of an object (Fig. $2 E$; Sham $=43 \pm$ $5.1 \%, \mathrm{RE} / \mathrm{Rh}=19 \pm 6.0 ; p=0.009$, unpaired Student's $t$ test). The RE/Rh group showed less interest toward the displaced object compared with the Sham group, suggesting that the RE/Rh 
A Single Unit Recording

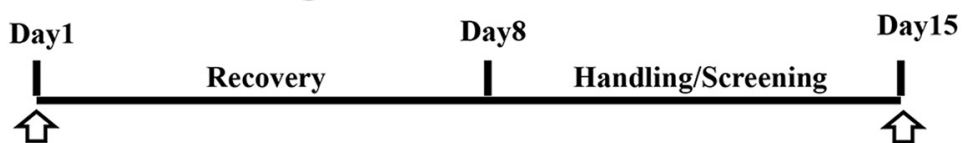

Electrolytic lesion

\& Drive implantation

B

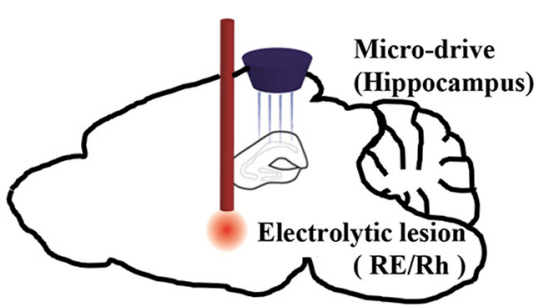

C

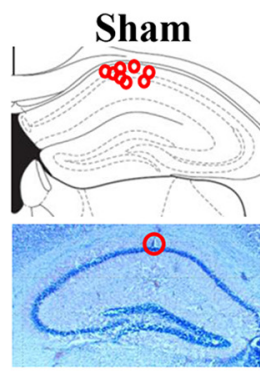

Hippocampal CA1

place cells recording starts

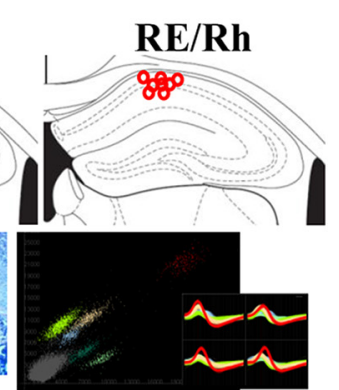

D

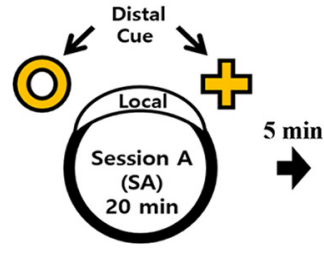

Local cue rotation

(Counterclockwise 90)

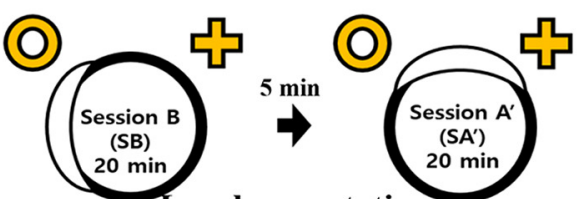

Local cue rotation

(Clockwise 90,

Counterclockwise 270)

\section{$\mathbf{E}$}
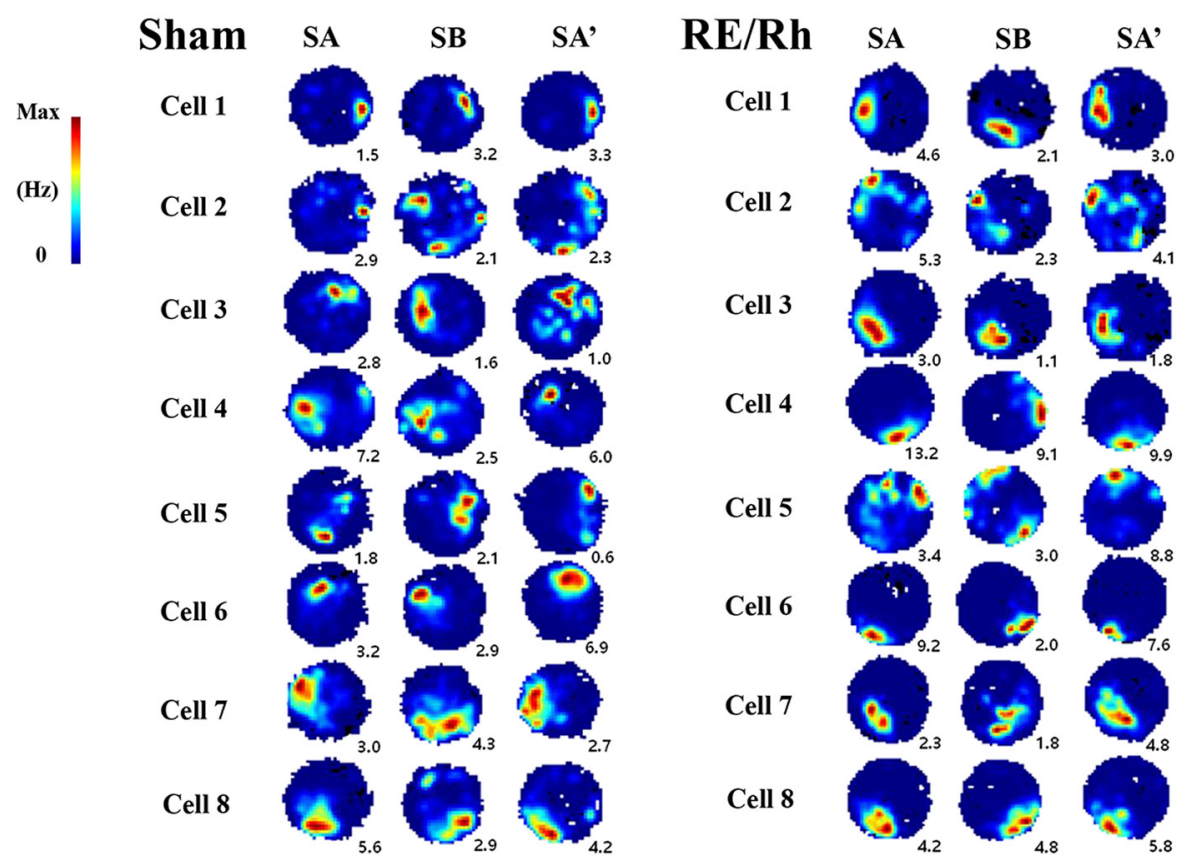

Figure 3. CA1 place cells recording to investigate the roles of RE/Rh on place cell properties. $A$, Schedules for investigating the roles of RE/Rh on single-unit activities of CA1 place cells. $B$, Schematic diagram for CA1 place cell recording using RE/Rh lesion mice. C, Distribution of recording sites and samples of single-unit cluster cutting. $\boldsymbol{D}$, Single-unit recording paradigm during which the local cue position was rotated. $\boldsymbol{E}$, Samples of place maps from the Sham and RE/Rh groups across the three sessions.

lesion influenced the ability to detect or use the altered positional information of objects.

$\mathrm{RE} / \mathrm{Rh}$ lesion influences spatial recognition of CA1 place cells after cue relocation

Next, single-unit recordings of CA1 pyramidal cells were conducted to examine the effects of RE/Rh lesion on place cell activities (Fig. $3 A, B$ ). Recording area was mainly restricted to the intermediate CA1 $(\sim 0.8-1.5 \mathrm{~mm}$ lateral to the sagittal midline) for both groups (Fig. 3C) to avoid positional bias of recorded place cells (Henriksen et al., 2010; Ito and Schuman, 2012; Nakazawa et al., 2016). To measure electrophysiological patterns of spatial representation of CA1 place cells when the cue location was modified, recordings were conducted in three consecutive sessions with $5 \mathrm{~min}$ intersession intervals: SA, SB, and SA'. All sessions were provided with static distal and local spatial cues. A 
Table 2. Characteristics of CA1 place cells from the Sham and RE/Rh groups

\begin{tabular}{lcc}
\hline & \multicolumn{1}{c}{ Sham } & $\mathrm{RE} / \mathrm{Rh}$ \\
\hline Mean firing rate $(\mathrm{Hz})$ & $1.10 \pm 0.112$ & $0.76 \pm 0.066^{*}$ \\
Burst/total spike ratio (\%) & $0.39 \pm 0.013$ & $0.43 \pm 0.015$ \\
In-field firing rate (Hz) & $2.12 \pm 0.160$ & $1.47 \pm 0.134^{* *}$ \\
In-field/out-field rate & $27.34 \pm 2.551$ & $33.38 \pm 13.063$ \\
Place field size $\left(\mathrm{cm}^{2}\right)$ & $94.83 \pm 4.061$ & $83.72 \pm 2.902^{*}$ \\
Spatial coherence & $0.963 \pm 0.0031$ & $0.954 \pm 0.009^{* *}$ \\
Running speed (cm/s) & $6.23 . \pm 0.933$ & $6.77 \pm 0.383$ \\
\hline
\end{tabular}

The values from three sessions, $S A, S B$, and $S A^{\prime}$, were averaged (unpaired two-tailed $t$ test, ${ }^{*} p<0.05,{ }^{* *} p<0.01$ ).

local cue was rotated in SB and rotated back to the original location in SA' (see Materials and Methods; Fig. 3D). Basic properties of place cells from the three 20 min sessions were analyzed to determine the characteristics of place cells from each group. Sample place maps in each group are shown in Figure $3 E$. The average running speed of mice was not significantly different between groups $($ Sham $=6.23 \pm 0.933 \mathrm{~cm} / \mathrm{s}, \mathrm{RE} / \mathrm{Rh}=6.77 \pm 0.383 \mathrm{~cm} / \mathrm{s}$; $p=0.649)$. The values of spatial parameters of individual place neurons were averaged over the three sessions and represented as a group mean \pm SEM in Table 2 . Because the three sessions were conducted consecutively, we also performed two-way ANOVA with repeated measures to observe effects of groups and sessions (Fig. $4 A$ ).

First, we assessed the changes of firing activity of CA1 place cells across the three sessions. Figure $4 B$ shows that the mean firing rate was significantly different between groups $\left(F_{(1,127)}=\right.$ $5.624, p=0.019)$ and sessions $\left(F_{(1.42,180.63)}=8.487, p=0.001\right)$ and there was a group ${ }^{\star}$ session interaction $\left(F_{(1.42,180.63)}=6.311\right.$, $p=0.006)$. To analyze the group ${ }^{*}$ session interaction further, comparisons between groups within each session using LSD post hoc analyses were conducted. In response to the local cue changes as the sessions proceeded, the Sham group changed its firing rates, resulting in the increased firing rates in $\mathrm{SB}$ and $\mathrm{SA}^{\prime}$ compared with SA (SA vs SB, $p=0.001$; $\mathrm{SA}_{\mathrm{vs}} \mathrm{SA}^{\prime}, p<0.001$ ). Firing rates of the $\mathrm{RE} / \mathrm{Rh}$ group, however, did not change over time (SA vs $\mathrm{SB}, p=0.157$; $\mathrm{SA}$ vs $\left.\mathrm{SA}^{\prime}, p=0.694\right)$. In within-sessions analyses, firing rates of the RE/Rh group and the Sham group were similar in SA (Sham $=0.90 \pm 0.109, \mathrm{RE} / \mathrm{Rh}=0.78 \pm 0.084, p=$ $0.434)$. However, firing rate of the Sham group became significantly higher than that of the RE/Rh group in SB ( Sham $=1.11 \pm$ $0.121, \mathrm{RE} / \mathrm{Rh}=0.67 \pm 0.061, p=0.005)$, as well as in $\mathrm{SA}^{\prime}$ $($ Sham $=1.29 \pm 0.131, \mathrm{RE} / \mathrm{Rh}=0.82 \pm 0.082, p=0.007)$.

Second, spatial coherence of CA1 place cells, which indicates the smoothness of firing rate changes toward the peak of a place field, were measured. As shown in Figure $4 C$, spatial coherence was significantly different between groups $\left(F_{(1,127)}=7.403, p=\right.$ $0.007)$, but not between sessions $\left(F_{(2,254)}=0.460, p=0.632\right)$; however, there was a group ${ }^{\star}$ session interaction $\left(F_{(2,254)}=3.504\right.$, $p=0.032)$. Post hoc analyses using LSD indicated that the RE/Rh group reduced its coherence values as the sessions proceeded (SA vs $\mathrm{SB}, p=0.045$; $\mathrm{SA}$ vs $\left.\mathrm{SA}^{\prime}, p=0.042\right)$, whereas the Sham group remained similar ( $\mathrm{SA}$ vs $\mathrm{SB}, p=0.367$; $\mathrm{SA}$ vs $\mathrm{SA}^{\prime}, p=0.193$ ). In within-session analyses, there were no group differences in SA $($ Sham $=0.9609 \pm 0.00251, \mathrm{RE} / \mathrm{Rh}=0.9579 \pm 0.00332, p=$ 0.461 ); however, spatial coherence of the RE/Rh group was significantly reduced compared with the Sham group in SB $($ Sham $=0.9633 \pm 0.00233, \mathrm{RE} / \mathrm{Rh}=0.9517 \pm 0.00322, p=$ $0.003)$ and $\mathrm{SA}^{\prime}($ Sham $=0.9647 \pm 0.00298, \mathrm{RE} / \mathrm{Rh}=0.9509 \pm$ $0.00392, p=0.005)$.

We also assessed whether the field size changes across the sessions because field size in general was reported to be responsive to cue information changes (Lee et al., 2004; Knierim and
Hamilton, 2011; Knierim et al., 2014). As shown in Figure 4D, there was a group difference in the place field size $\left(F_{(1,127)}=\right.$ $4.255, p=0.041)$, but not between sessions $\left(F_{(2,254)}=1.964, p=\right.$ $0.142)$ or in the group ${ }^{*}$ session interaction $\left(F_{(2,254)}=2.362\right.$, $p=0.096)$. The Sham group increased its field size in SB and SA' compared with SA (SA vs $\mathrm{SB}, p=0.010$; $\mathrm{SA}$ vs $\mathrm{SA}^{\prime}, p=0.022$, paired Student's $t$ test), whereas that of the RE/Rh group remained similar ( $\mathrm{SA}$ vs SB, $p=0.894$; $\mathrm{SA}$ vs SA', $p=0.903$, paired Student's $t$ test). In within-session analyses, there were no group differences in SA (Sham $=89 \pm 3.8, \mathrm{RE} / \mathrm{Rh}=84 \pm 3.6, p=0.36$, unpaired Student's $t$ test). However, place field size of the Sham group was significantly larger compared with the RE/Rh group in $\mathrm{SB}(\mathrm{Sham}=98 \pm 4.9, \mathrm{RE} / \mathrm{Rh}=84 \pm 3.4, p=0.018$, unpaired Student's $t$ test) and in $\mathrm{SA}^{\prime}$ (Sham $=98 \pm 4.8, \mathrm{RE} / \mathrm{Rh}=84 \pm 3.4$, $p=0.017$, unpaired Student's $t$ test).

The features of CA1 place cells (firing rate, coherence, and field size) showed no group differences in the first sessional exposure to the environment (SA). However, group differences appeared during $\mathrm{SB}$ and $\mathrm{SA}^{\prime}$, when a positional change of a local cue was introduced.

\section{$\mathrm{RE} / \mathrm{Rh}$ lesion affects between-session similarity of CA1 place maps with cue rotations}

Similarity analyses with local cue rotation (SA-SB)

The result observed in the object location recognition task implies that the RE/Rh lesion influenced the behavioral performance to recognize the change of spatial relationships between the objects and spatial cue cards compared with the former training phase. To investigate neuronal response to the manipulated spatial relationships in parallel with the behavioral performance, the spatial correlation of CA1 place maps between two environments, SA and SB, where the local cue was rotated $90^{\circ}$ counterclockwise while the distal cue remained stationary, was analyzed (examples for analysis procedure are shown in Fig. 5). In Figure $5 A$, the likeness between two place rate maps was obtained by calculating the pixel-by-pixel correlation between place rate maps and defined as similarity, while local cue similarity was used to figure out the likeness between a place map of SA and a rotated map of SB ( $90^{\circ}$ clockwise). The purpose of local cue similarity analysis was to verify the influence of the local cue in our recording setup. In addition, to quantify the likeness of place maps with the local cue rotation, the pixel-by-pixel correlation between two place maps was calculated while rotating the place map of SB with $5^{\circ}$ intervals and the correlation scores were presented over the rotated degrees as rotational similarity. The rotated degree that produced the highest correlation score was taken as rotation angle for the further analyses, and the highest correlation score was termed as maximum similarity (Fig. $5 B$ ). Rotation angle provided additional information about cue preference of each place cell in response to the local cue rotation, which was also presented as cue dependency (Fig. 5C). For example, place cells' tendency to follow the local cue or the distal cues was categorized in three groups according to rotation angle values; "stay" follows the distal cue, "rotation" follows the local cue, and "remapped" for the remaining values. Distribution of place fields relatively to the center of an arena might affect the result of similarity analyses, so we confirmed that the distances between place fields and the center of an arena were not different between groups $($ Sham $=5.3 \pm 0.31 \mathrm{~cm}, \mathrm{RE} / \mathrm{Rh}=6.1 \pm$ $0.37 \mathrm{~cm}, p=0.1$, unpaired Student's $t$ test).

In Figure $6 A$, rotational similarity shows that overall angular distribution of correlations of the $\mathrm{RE} / \mathrm{Rh}$ group was different compared with the Sham group $(p<0.001$, Watson-Williams 
A

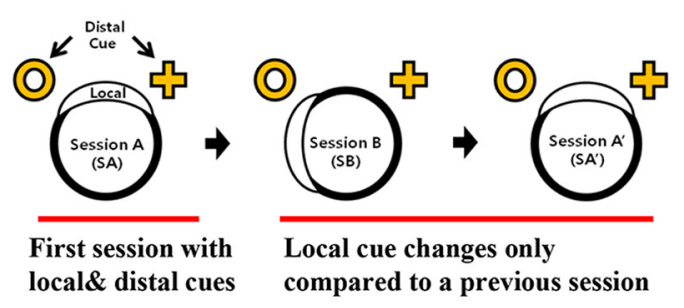

C

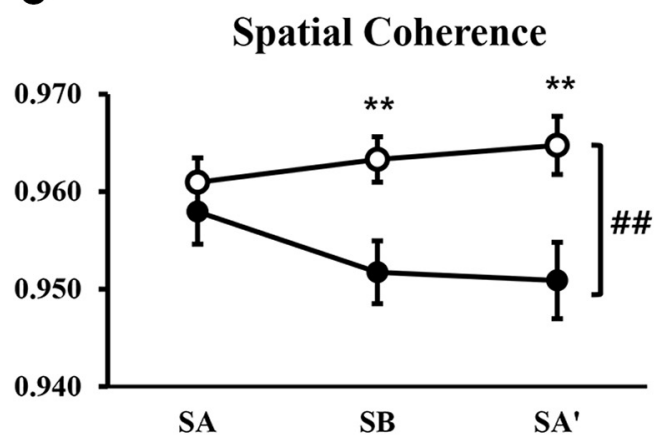

B

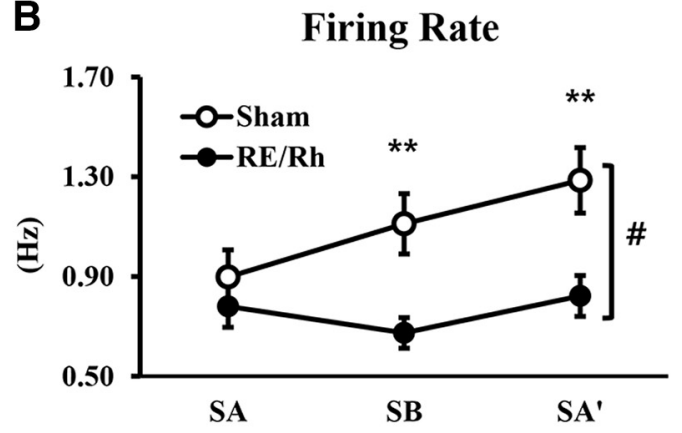

D

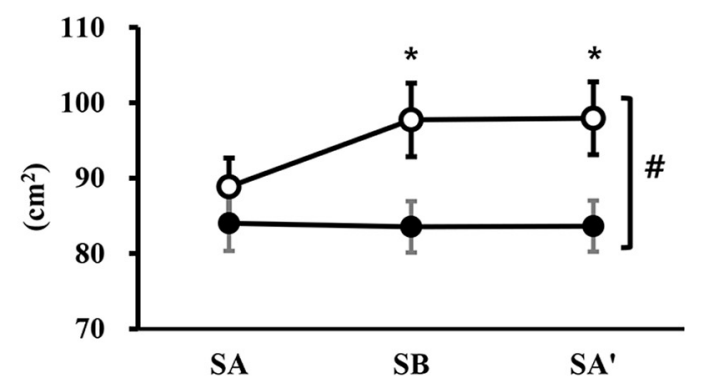

Figure 4. Spatial representation properties of CA1 place cells across the three sessions. $A$, Recording paradigm to induce changes in the local cue positions as sessions proceeded. $B$, Firing rate showing group differences. C, Spatial coherence showing group differences. D, Place field size showing group differences (overall group effects: \#p $<0.05$, \#\#p $<0.01$; within-session group difference, ${ }^{*} p<0.05,{ }^{* *} p<0.01$ ).

test). Similarity (Fig. 6B, left) significantly differed between groups $($ Sham $=0.25 \pm 0.029, \mathrm{RE} / \mathrm{Rh}=0.15 \pm 0.023, p=0.004$, unpaired Student's $t$ test). Although the group differences in field size was statistically significant (Fig. 4D), the similarity score still showed group differences even after matching the average field sizes of the two groups by removing data with large field size in the Sham group ( $p=0.026$, unpaired Student's $t$ test). Interestingly, the reduced similarity score of the RE/Rh group became similar to that of the Sham group when the place map of SB was rotated $90^{\circ}$ clockwise, as shown by local cue similarity (Fig. $6 B$, middle; Sham $=0.39 \pm 0.035, \mathrm{RE} / \mathrm{Rh}=0.32 \pm 0.035, p=0.142$, unpaired Student's $t$ test). Furthermore, maximum similarity did not show significant group differences (Fig. $6 B$, right; Sham $=$ $0.62 \pm 0.033, \mathrm{RE} / \mathrm{Rh}=0.54 \pm 0.039, p=0.136$, unpaired Student's $t$ test).

To examine the possibility that these different similarity values may have been resulted from cue dependency, rotation angles from individual place cells responses were analyzed. The length of bars corresponded to the number of place cells at each angle and its distribution is represented in Figure $6 C$, left. Rotation angles from both groups were similarly distributed as shown by the vector properties of the Sham group $\left(\right.$ mean $=67.76^{\circ}$, length $=$ $0.64, p<0.01$, Rayleigh test) and the $\mathrm{RE} / \mathrm{Rh}$ group (mean $=60$. $63^{\circ}$, length $=0.67, p<0.01$, Rayleigh test), resulting in no group difference ( $p=0.82$, unpaired Student's $t$ test). Similar to the results in the rotation angle distributions, cue dependency was not affected by the RE/Rh lesion because both groups showed more preference to follow the local cue. (Fig. $6 C$, right, $\chi^{2}=$ 0.661. $p=0.72, \chi^{2}$ ).

In brief, the similarity analyses showed that the RE/Rh lesion reduced the similarity between SA and SB when the local cue was rotated (similarity). Interestingly, even though the quality of the spatial representation appeared to be lower in the lesion group, similarity scores of place cells became similar if individual rate maps were rotated as shown by local cue similarity and maximum similarity. Furthermore, cue dependency was not influenced by the RE/Rh lesion and local cue showed stronger influences in both groups.

These results suggest that the RE/Rh lesion attributed to spatial information process of CA1 place cells in comparing similar environments with different spatial cue relationships.

Similarity analyses with local cue rotation toward a different direction $\left(S B-S A^{\prime}\right)$

Next, we observed whether aforementioned phenomena are replicable when the local cue was rotated at a different direction as in $\mathrm{SA}^{\prime}$. The same methods on similarity analyses were used on the similarity analyses between SB and $\mathrm{SA}^{\prime}$, in which the local cue was rotated back to the original position $\left(90^{\circ}\right.$ clockwise; Fig. $6 D-F)$. The distributions of rotational similarity significantly differed between groups $(p<0.0001$, Watson-Williams test), as shown in Figure $6 D$, and there was also a group difference in similarity (Fig. $6 E$, left), but local cue similarity (Fig. 6E, middle) and maximum similarity (Fig. 6E, right) differed between the two groups. In addition, the distributions of rotation angles were similar between groups (Sham: mean $=289.57^{\circ}$, length $=0.53, p<0.01$, Rayleigh test; RE/Rh: mean $=288.41^{\circ}$, length $=0.63, p<0.01$, Rayleigh test) in response to the local cue position near $270^{\circ}$ (Fig. $6 \mathrm{~F}$, left), resulting in no group difference ( $p=0.83$, unpaired Student's $t$ test). The cue dependency category also indicates that both groups had similar tendency to follow either cue (Fig. 6F, right; $\left.\chi^{2}=2.984, p=0.22, \chi^{2}\right)$. Overall, the results of similarity analyses of the comparison between $\mathrm{SB}$ and $\mathrm{SA}^{\prime}$ replicated those of the comparison between SA and SB. 
A

Cell 8 in Sham group

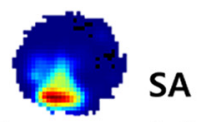

Cross correlation

Between SA and Rotated SB in $5^{\circ}$ bin
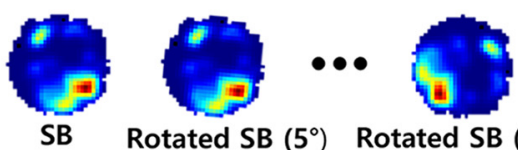

Rotated SB (5) Rotated SB $\left(90^{\circ}\right)$

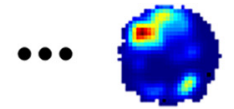

Rotated SB $\left(180^{\circ}\right)$ $\bullet \bullet \bullet$

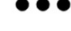

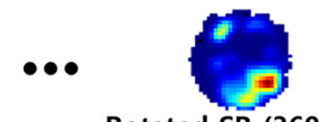

Rotated SB $\left(360^{\circ}\right)$

\section{Rotational Similarity}

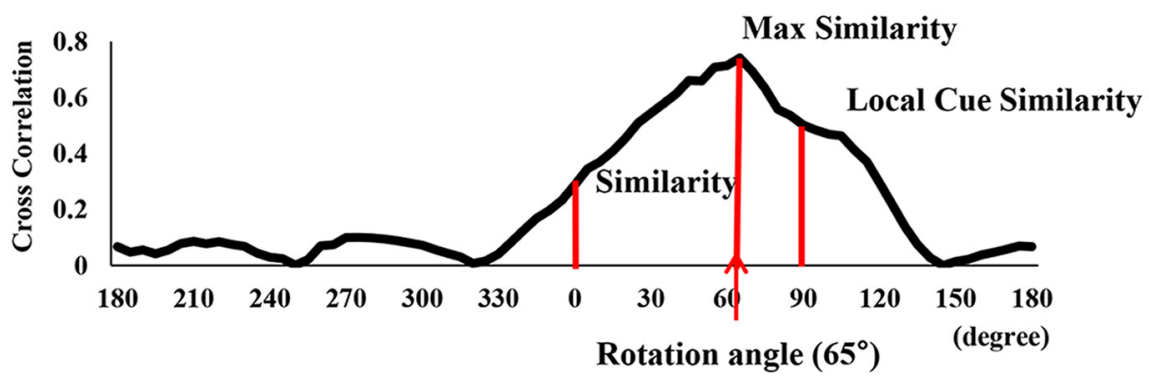

B

\begin{tabular}{|l}
$\begin{array}{l}\text { Similarity } \\
\text { Cross correlation SA vs. SB } \\
=0.29\end{array}$ \\
\hline $\begin{array}{l}\text { Local Cue Similarity } \\
\text { Cross correlation } \\
\text { SA vs. rotated SB aligned to local cue } \\
=0.66\end{array}$ \\
$\begin{array}{l}\text { Max Similarity } \\
\text { The highest cross correlation }=0.74\end{array}$ \\
$\begin{array}{l}\text { Rotation Angle } \\
\text { The degree leading to Max Similarity }=65^{\circ}\end{array}$
\end{tabular}

C

Stay

Rotation Angle $315 \sim 45^{\circ}$

\section{Rotation}

Rotation Angle $45 \sim 135^{\circ}$

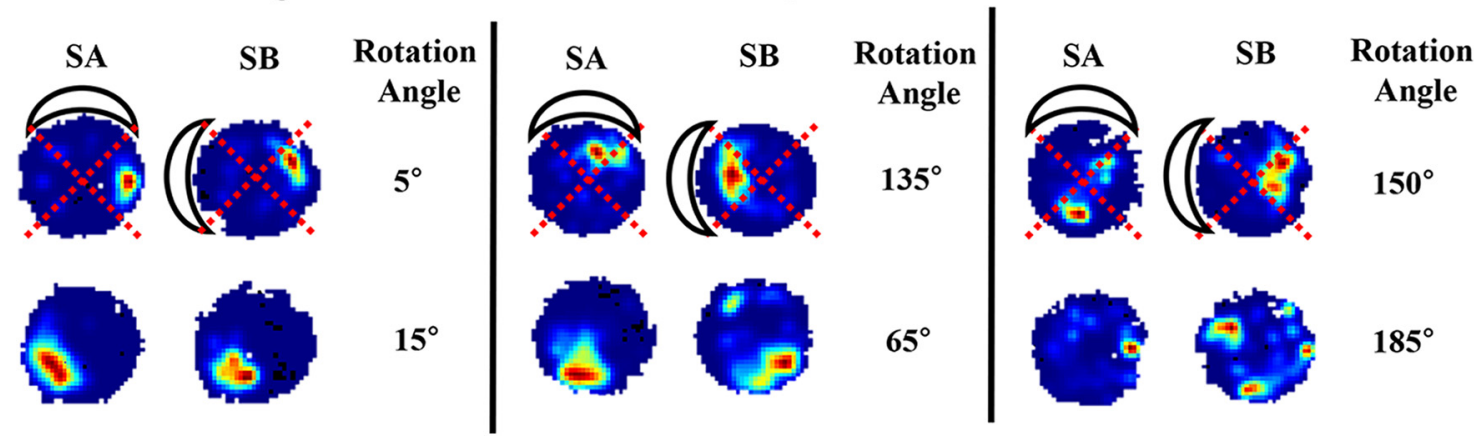

Figure 5. Illustrations of similarity analyses and representative samples for comparison between SA and SB.A, Procedure to calculate rotational similarity described with place map samples from cell number 8 in the Sham group. The firing rate in each pixel from the place map in SA was correlated with that in SB and then the place map in SB was circularly shifted by $5^{\circ}$ clockwise to recalculate the correlation with that in SA. This procedure was repeated while rotating the place map in SB by $\sim 0-360^{\circ}$ and the distribution of correlation values between $S A$ and rotated SB was presented along with each degree of the rotated angle. $\boldsymbol{B}$, Representative samples for parameters. Cross-correlations values at $0^{\circ}, 90^{\circ}$, and rotation angle in the rotational similarity distribution were termed as similarity, local cue similarity, and maximum similarity, respectively (see Materials and Methods). $C$, Neuronal responses to cue positional change (cue dependency) were classified in three categories according to rotation angles and samples in each category are presented: stay, rotation, and remapped. 
A

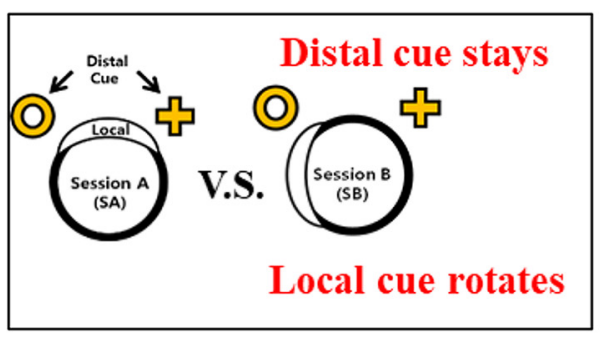

B
Similarity
Local Cue
Similarity
Max Similarity
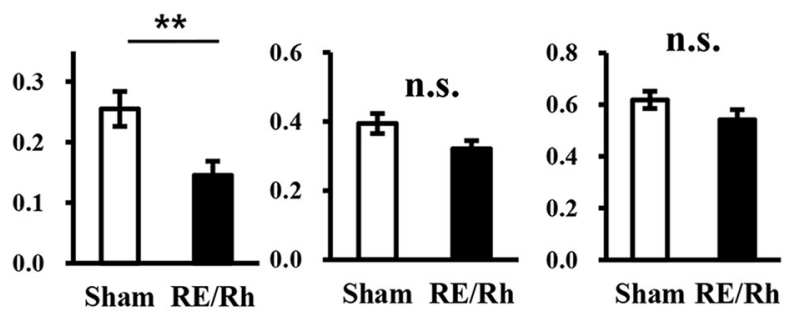

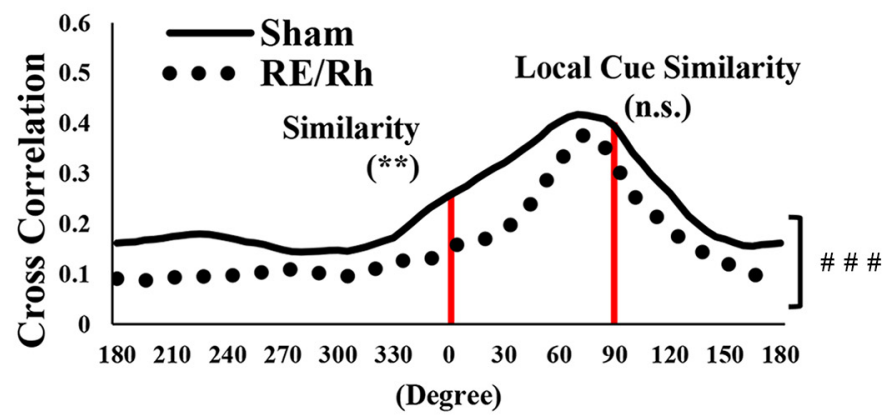

C

Rotation Angle<smiles>CC(C)=C1CCCCCCCCCC1C</smiles>

Sham
Rotational Similarity

(Degree)

\section{D}

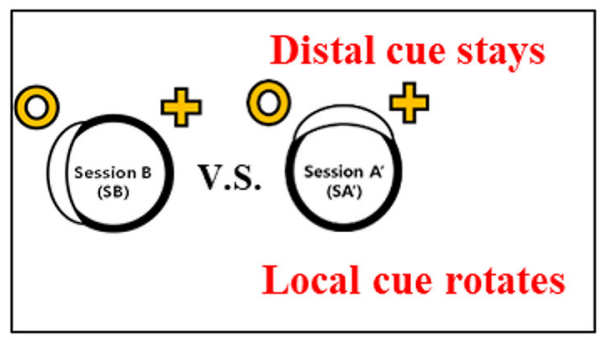

E
Local Cue Similarity
Max Similarity

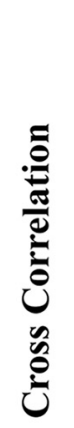

Rotational Similarity

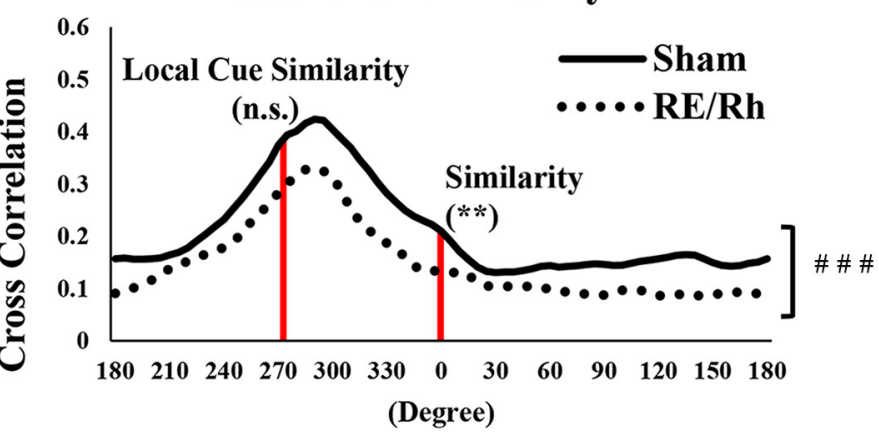

$\mathbf{F}$

RE/Rh

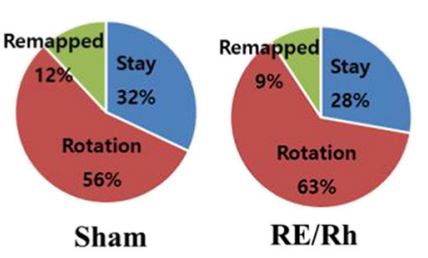

Cue Dependency Category

Sham

$\mathrm{RE} / \mathrm{Rh}$
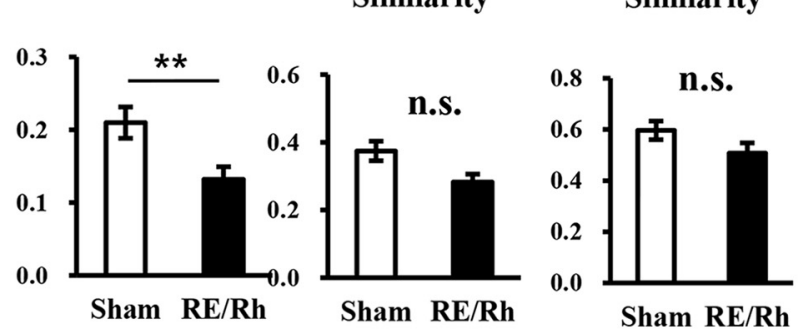

Rotation Angle

Cue Dependency Category

Figure 6. Similarity analyses with cue rotation. $A-C$, Place cell representation analyses comparing SA and SB. A, Distributions of rotational similarity from the two groups were significantly different (overall group effects, \#\#\# $<0.001$ ). B, Similarity score was significantly decreased in the RE/Rh group. Local cue similarity and maximum similarity scores were not significantly different between groups (unpaired two-tailed $t$ test, ${ }^{* *} p<0.01$ ). C, Distributions of rotation angles where maximum similarity was calculated and cue dependency categories of individual place cell responses. Stay contains neurons with rotation angle of $315 \sim 45^{\circ}$; rotation contains neurons with rotation angle of $45 \sim 135^{\circ}$ following the local cue; remapping are the remaining cells that are not classified as stay or rotation). $\mathbf{D}-\boldsymbol{F}$, Place cell representation analyses comparing $S B$ and $S A^{\prime}$. D. Distributions of rotational similarity from the two groups were significantly different (overall group effects, \#\# $<0.001)$. $E$, Similarity score was significantly decreased in the RE/Rh group. Local cue similarity and maximum similarity score were not significantly different between groups (unpaired two-tailed $t$ test, ${ }^{* *} p<0.01$ ). $\boldsymbol{F}$, Distributions of rotation angles and cue dependency categories of individual place cell responses. Stay contains neurons with the rotation angle of $315 \sim 45^{\circ}$; rotation contains neurons with rotation angle of $225 \sim 315^{\circ}$ following the local cue; remapping contains cells that are classified as neither stay nor rotation. 
A

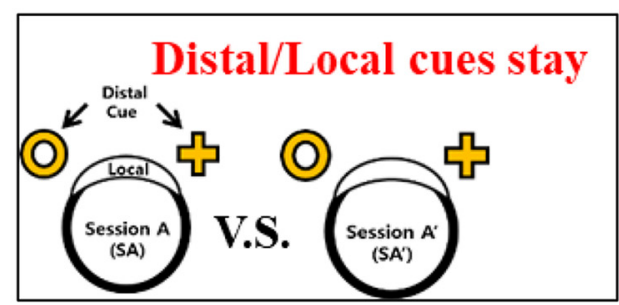

B

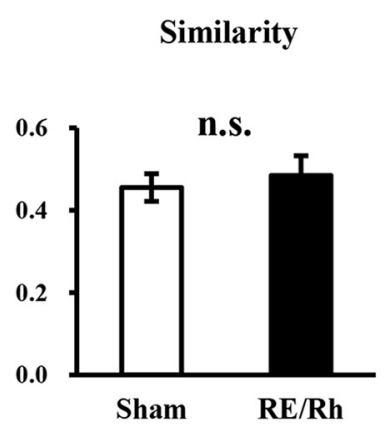

Max Similarity

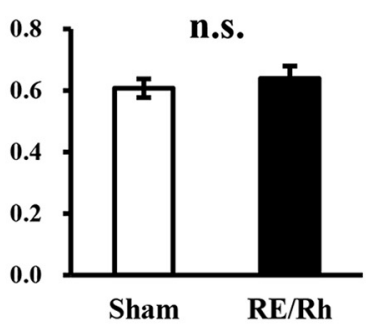

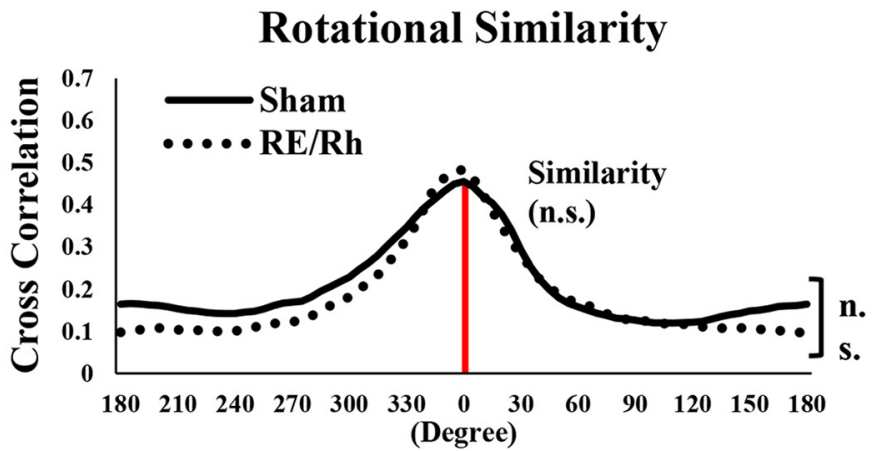

C

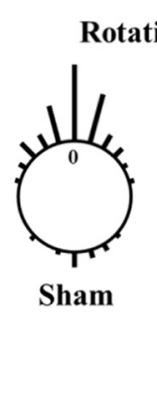

Rotation Angle

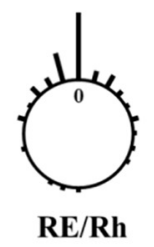

Cue Dependency Category

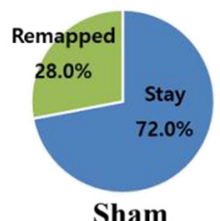

Sham

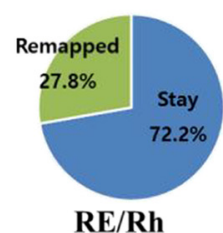

Figure 7. Place representation analyses comparing $S A$ and $S A^{\prime} . A$, Distribution of rotational similarity scores from the two groups were not significantly different. $B$, Similarity score and maximum similarity scores were similar between groups. C, Distribution of rotation angles and cue dependency categories of individual place cell responses. Stay contains neurons with rotation angle of $\sim 315-45^{\circ}$; remapping were neurons with a rotation angle of $\sim 45-315^{\circ}$.

$\mathrm{RE} / \mathrm{Rh}$ lesion does not alter stability of place maps in familiar environments. (SA-SA')

We next analyzed whether the $\mathrm{RE} / \mathrm{Rh}$ lesion affected the place cell's stability to represent familiar environments by comparing SA and SA', both of which have identical cue arrangements. Both groups showed similar distributions of rotational similarity (Fig. $7 A ; p=0.16$, Watson-Williams test). Neither group showed a significant difference in similarity (Sham $=0.46 \pm 0.033, \mathrm{RE} /$ $\mathrm{Rh}=0.48 \pm 0.048, p=0.619)$ or maximum similarity $($ Sham $=$ $0.61 \pm 0.030, \mathrm{RE} / \mathrm{Rh}=0.64 \pm 0.040, p=0.530)($ Fig. $7 B)$. In addition, no differences were observed in the distributions of rotation angles between the Sham group (mean $=-0.99^{\circ}$, length $=0.62, p<0.01$, Rayleigh test) and the RE/Rh group (mean $=-0.69^{\circ}$, length $=0.68, p<0.01$, Rayleigh test), as shown by vectors from both groups near $0^{\circ}$ (Fig. $7 C$, left) and unpaired Student's $t$ test $(p=0.55)$. Unsurprisingly, the cue dependency category also showed that place cells of both groups had a similar tendency to stay or to be remapped (Fig. $7 C$, right, $\left.\chi^{2}=0.001 p=0.98, \chi^{2}\right)$. Overall, the RE/Rh lesion did not alter the stability to represent familiar environments.

Because similarity scores throughout all between-session comparisons may be influenced by place field size and because the field sizes of the two groups were different (Fig. 4D), we assessed the relationship between field size and between-sessions similarity scores with Pearson correlation. Correlation coefficients indicated that field sizes were positively correlated with similarity scores in all between-session similarity analyses (Table 3), meaning that place cells with greater the field size tend to have a greater similarity score. However, from the finding that similarity scores in familiar environments ( $\mathrm{SA}$ vs $\mathrm{SA}^{\prime}$ ) did not show group differences even though fields size of the Sham group in $\mathrm{SA}^{\prime}$ was bigger than the RE/Rh group, we can conclude that place field size is not the only factor influencing the value of similarity
Table 3. Correlation between place field size and similarity score

\begin{tabular}{llll}
\hline & $\begin{array}{l}\text { Field size vs } \\
\text { similarity of SA-SB }\end{array}$ & $\begin{array}{l}\text { Field size vs } \\
\text { similarity of SB-SA' }\end{array}$ & $\begin{array}{l}\text { Field size vs } \\
\text { similarity of SA-SA' }\end{array}$ \\
\hline All groups & $r=0.612, p<0.001$ & $r=0.574, p<0.001$ & $r=0.266, p<0.001$ \\
Sham & $r=0.639, p<0.001$ & $r=0.592, p<0.001$ & $r=0.300, p=0.009$ \\
RE/Rh & $r=0.455, p=0.001$ & $r=0.436, p=0.001$ & $r=0.284, p=0.037$ \\
\hline
\end{tabular}

Pearson correlation coefficient score $(r)$ and $p$-value were calculated for comparison between the difference environments (SA-SB and SB-SA' cross-correlation) and the same environments (SA-SA' cross-correlation).

scores (Lee et al., 2004; Larkin et al., 2014). In fact, both the consistent field size over different sessions and the lower similarity results of the $\mathrm{RE} / \mathrm{Rh}$ group suggest that the $\mathrm{RE} / \mathrm{Rh}$ group is less capable of detecting cue manipulation than the Sham group. Therefore, the results suggest that the Sham group is more capable of detecting cue manipulations.

\section{$\mathrm{RE} / \mathrm{Rh}$ lesion reduced individual variations in rotational similarity}

Rotational similarity distributions of individual animals were plotted to assess the possibility that few animals may have biased the correlation analysis (Fig. 8). Interestingly, animals in the Sham group had diverse correlation patterns regarding the locations of distal/local cues compared with the RE/Rh group, although the tendency to have maximum correlation values around the location of a local cue was present in both groups. Previous studies reported that, in normal mice, the activity of CA1 place cells are influenced by both distal/local cues in response to mismatching cues (Knierim, 2002; Lee et al., 2004; Knierim and Hamilton, 2011). Our data show that, in contrast to normal mice, the ability of place cells to represent distal cue attenuates with the RE/Rh lesion. Reduction of place cells in the $\mathrm{RE} / \mathrm{Rh}$ group to possess distal cue information was also reflected in the reduced similarity score of the RE/Rh group (Fig. $6 B, E$, left). 
A

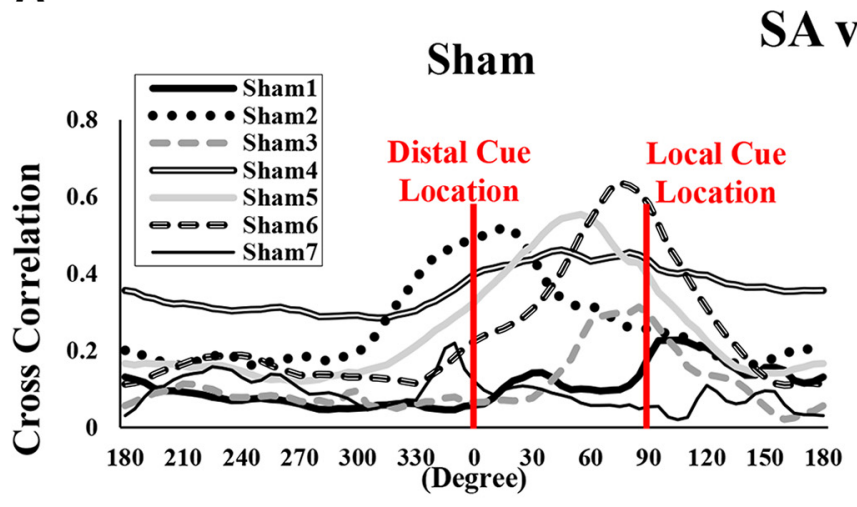

\section{SA vs SB}

B

\section{SB vs SA'}
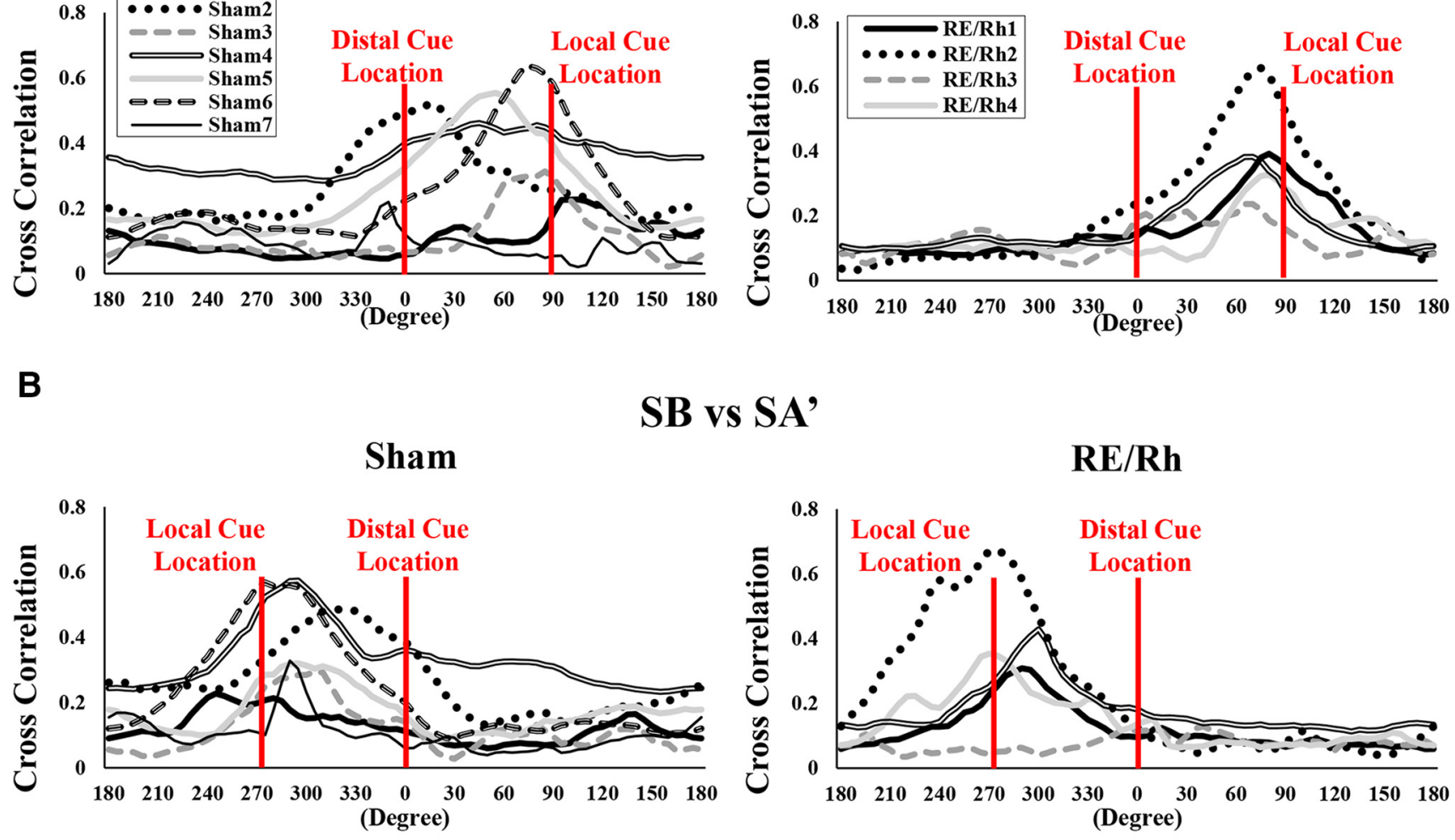

RE/Rh

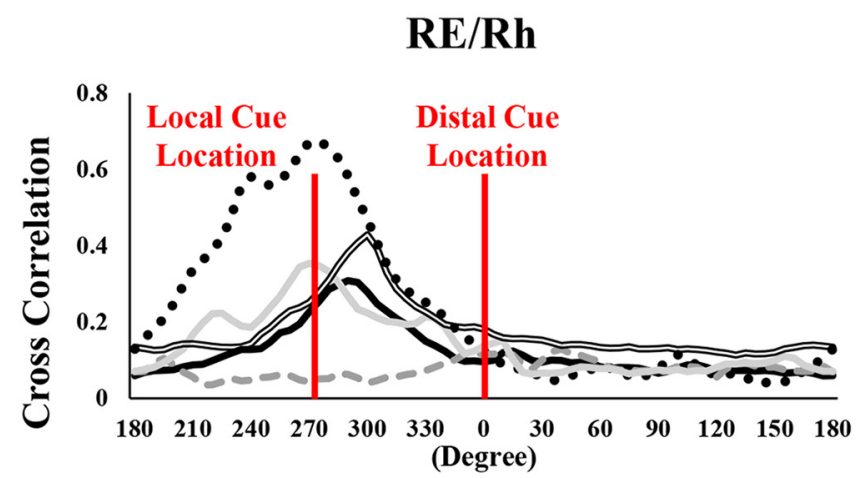

C

SA vs SA'

\section{Sham}

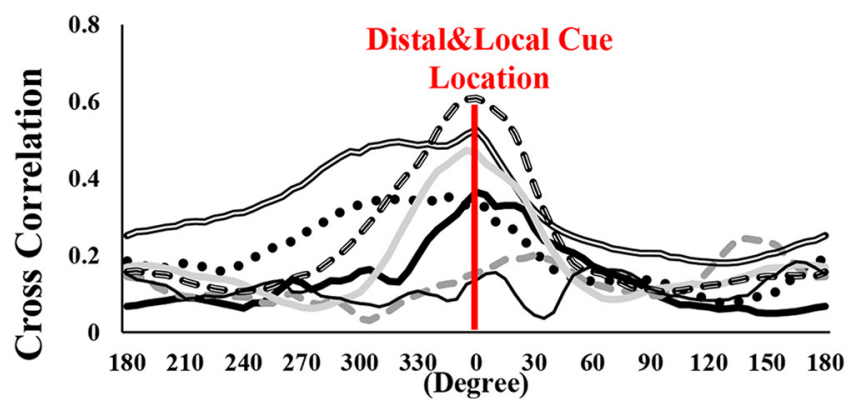

RE/Rh

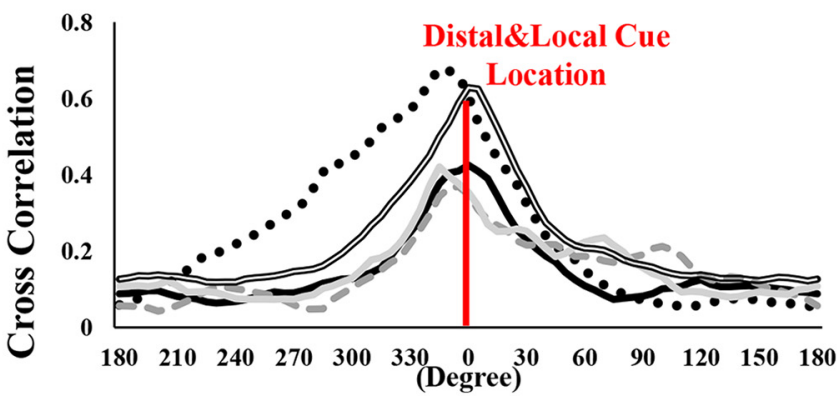

Figure 8. Distributions of rotational similarity from individual mice. $\boldsymbol{A}$, Rotational similarity comparing SA and SB over the rotated degrees. $\boldsymbol{B}$, Rotational similarity comparing SB and SA over the rotated degrees. C, Rotational similarity comparing SA and $S A^{\prime}$ over the rotated degrees.

In summary, the similarity analyses and cue rearrangement indicates that the $\mathrm{RE} / \mathrm{Rh}$ lesion influenced spatial representation of place cells on comparing environments when there were changes in cue positional information, whereas it did not affect the spatial representation to compare identical environments.

\section{Discussion}

This study demonstrates that the ventral midline thalamus $(\mathrm{RE} / \mathrm{Rh})$ is critically involved in hippocampal-dependent spatial function by integrating ongoing detail changes of the environment. The lesion of RE/Rh decreased behavioral performance in the object location recognition task, indicating that the lesion group appeared to recognize the locational change to some extent, but was not able to integrate or use it for spatial representation in collaboration with the hippocampus as much as the Sham group. This behavioral result also appeared to be in parallel with the place cell activities. Indeed, the lesion altered the spatial representation properties of CA1 place cells under the cue relocations, but not under the first sessional exposure to the cues. As the local cue rotated, the spatial representation properties of the place cells in the lesion group such as firing rates, spatial coherence, and place field size showed different patterns compared with the Sham group. In similarity analyses, we found that the lesion affected spatial representation of place cells in response to cue rotations as shown by reduced similarity values and altered distributions of Rotational angles. However, the ability to recognize the same environments was not affected. 


\section{Roles of $\mathrm{RE} / \mathrm{Rh}$ with cue location changes}

Impaired performance in the object location recognition task following RE/Rh lesion implies that the spatial information processing system does not work properly for recognizing changes in object locations and associating them with previous experience; this was true only during test phase II, not during test phase I. This result is not exactly consistent with previous work in which $\mathrm{RE} / \mathrm{Rh}$ had no effect on the object location recognition task (Barker and Warburton, 2018). This discrepancy may be caused by the methodological difference in making lesions (electrolytic vs excitotoxic lesion) and the extension of the lesion, which may differentially affect the fiber connectivity (Corbit and Balleine, 2000), or experimental setups such as cue configurations (Murai et al., 2007; Langston and Wood, 2010; Koob et al., 2013). Changes in the attentional state of the RE/Rh group may also have caused this discrepancy. $\mathrm{RE} / \mathrm{Rh}$ lesions may have reduced the attention span, thereby reducing the ability to discriminate between stationary and displaced objects with time progression because many studies have reported that $\mathrm{RE} / \mathrm{Rh}$ regulates attention and awareness during spatial tasks (Van der Werf et al., 2002; Cholvin et al., 2013, 2018). Nevertheless, our study shows that the lesion influenced the behavioral performance required to detect and use locational changes, but did not completely impair the performance. Many related brain regions such as the entorhinal and retrosplenial cortices and their possible information pathways have been reported for the mechanism of associating objects' location and spatial information from the context, especially in relation to the hippocampal CAlarea (Dere et al., 2005). CA1 may transmit neural signals on object-related information via the perirhinal cortex and lateral entorhinal cortex pathway, as well as spatial information via the parahippocampal and medial entorhinal cortex (MEC) pathway (Langston and Wood, 2010; Dolleman-van der Weel et al., 2017), to drive the different behavioral preference toward displace/stationary objects. Considering direct/indirect connections of $\mathrm{RE} / \mathrm{Rh}$ with $\mathrm{CA} 1, \mathrm{RE} / \mathrm{Rh}$ may influence the information transmissions of object and place configurations to modulate the contextual/spatial information-related episodic memory by interplaying with aforementioned brain regions.

In our study, behavioral deficits were also linked to physiological changes, as shown by altered spatial representation properties of CA1 place cells. For example, the firing rate of the lesion group was consistent, whereas that of the Sham group increased across the sessions. In fact, the increase in firing rate of CA1 place cells is considered to be involved in novelty detection and spatial information processing in altered environments (Karlsson and Frank, 2008; Larkin et al., 2014). In previous studies (Larkin et al., 2014), exposure to replacement of an object's location during an object location task substantially increased firing activities of pyramidal neurons in CA1, but not in CA3. This suggested that inputs to $\mathrm{CA} 1$ and $\mathrm{CA} 1$ itself, rather than the trisynaptic pathway via CA3, were more responsible for the increased firing rate of CA1 place cells during the detections of location changes (Langston and Wood, 2010; Larkin et al., 2014). Considering other studies showing that $\mathrm{RE} / \mathrm{Rh}$ makes synapses onto CAl directly rather than through the trisynaptic pathway via $\mathrm{CA} 3$, it is possible that direct information flow between $\mathrm{RE} / \mathrm{Rh}$ and $\mathrm{CA} 1$ is essential for detecting or integrating changes on cue positions. In addition, the coherence of place fields of the lesion group in our study was significantly decreased as the cue positional change was introduced, which was consistent with a previous study in which spatial coherence in the lesion group was disrupted solely during the novel environment (Cholvin et al., 2018). Our results showed that the RE/Rh lesion prevented CA1 place cells from detecting or using the novel changes on spatial relationships. In addition, the place field size of the Sham group became larger as the local cue rotated, consistent with previous cue dissociation studies in which CA1 place cells increased place fields in response to mismatching cue relationships (Lee et al., 2004; Knierim and Hamilton, 2011). However, the lesion group did not change their place field sizes, indicating that the lesion group was incapable of recognizing (or less responsive to) positional rearrangement of the local cue.

\section{Influences of $\mathrm{RE} / \mathrm{Rh}$ on spatial representation of distal/local cues}

In our similarity analyses, the RE/Rh lesion did not affect the ability to represent the same environments. However, the lesion influenced place cells' features to recognize the environment where spatial relationships between distal/local cue positions were rearranged. In particular, the reduced similarity score of the $\mathrm{RE} / \mathrm{Rh}$ group when the spatial relationship between distal and local cue changed indicates that the RE/Rh modulated CAl's spatial representations properties when there was a conflict in topological cue relationships upon revisit. However, the lesion did not affect local cue similarity, in which the positional information of the local cue was more influential than that of the distal cue, indicating that $\mathrm{RE} / \mathrm{Rh}$ lesion may not critically influence local cue information processing. These altered responses of place cells caused by lesion of the RE/Rh and corresponding changes in spatial representation may also have led to the altered performance in the object location recognition task.

Recent studies have revealed that the RE/Rh contains head direction cells and connects with various brain regions containing head direction cells such as the presubiculum and retrosplenial cortex (Jankowski et al., 2014). Therefore, the head direction system in the lesion group may have contributed to the altered responses of place cells toward rotational changes. In addition to the head direction systems, underlying neural circuits required to process the spatial relationships of distal/local cues could be affected by RE/Rh lesion.

CA1 place cells are known to show distinctive responses toward conflicting information of local and distal cues and these distinctive information are transmitted via different connections (Knierim and Hamilton, 2011; Park and Lee, 2016). MEC receives inputs from the presubiculum, retrosplenial, and postrhinal cortex, which are composed of grid cells and head direction cells to mediate distal cues more than local cues whereas CA3 response to local cues more (Yoganarasimha et al., 2006; Knierim et al., 2014). Through these two different inputs, CA1 place cells may distinctively receive both distal and local cue information (Renaudineau et al., 2007; Knierim and Hamilton, 2011). In fact, $\mathrm{RE} / \mathrm{Rh}$ may mediate spatial representation of CA1 place cells on distal/local cues by interplaying with those pathways. RE/Rh has direct connections with CA1, but not with CA3 (Vertes et al., 2007). Furthermore, RE/Rh also indirectly modulates CA1 activities through the EC and other cortical regions, as implicated in spatial navigation of alternation tasks and pattern separation/ completion in fear-conditioning tasks (Xu and Südhof, 2013; Ito et al., 2015). Considering this, the reduced similarity score may have resulted from the threshold changes of EC input to CA1 via malfunctioned connections between RE/Rh and CA1, whereas the unaffected values of local cue similarity may have been mediated more by intact anatomical input from CA3 to CA1. In short, $\mathrm{RE} / \mathrm{Rh}$ does not influence spatial representation of familiar envi- 
ronments, but rather affects spatial representation of different environments with manipulated arrangements of distal/local cues. Furthermore, this region appears to be less critically involved in processing local cue position than in processing the distal cue position to mediate distinctive signals of distal/local information through the neural circuit to CA1.

Together, our results show that the RE/Rh is involved in detection or integration of changes in cue positional relationships, which was induced by rotating the local cue while retaining the distal cue at the same position. Therefore, disruption of the $\mathrm{RE} / \mathrm{Rh}$ may result in altered performance on recognizing locational changes of objects and spatial cues.

Here, we showed that RE/Rh lesion influenced hippocampaldependent spatial memory as well as spatial representation of CA1 place cells, especially in response to cues' positional manipulation. Considering the intermingled circuits and modulating roles associated with hippocampal regions, the functional roles of the $\mathrm{RE} / \mathrm{Rh}$ in processing distinctive spatial components and interplaying circuits are worthy of further investigation.

\section{References}

Barker GRI, Warburton EC (2018) A critical role for the nucleus reuniens in long-term, but not short-term associative recognition memory formation. J Neurosci 38:3208-3217.

Brewin CR (2014) Episodic memory, perceptual memory, and their interaction: foundations for a theory of posttraumatic stress disorder. Psychol Bull 140:69-97.

Brown MW, Aggleton JP (2001) Recognition memory: what are the roles of the perirhinal cortex and hippocampus? Nat Rev Neurosci 2:51-61.

Calton JL, Stackman RW, Goodridge JP, Archey WB, Dudchenko PA, Taube JS (2003) Hippocampal place cell instability after lesions of the head direction cell network. J Neurosci 23:9719-9731.

Cassel JC, Pereira de Vasconcelos A, Loureiro M, Cholvin T, DalrympleAlford JC, Vertes RP (2013) The reuniens and rhomboid nuclei: neuroanatomy, electrophysiological characteristics and behavioral implications. Prog Neurobiol 111:34-52.

Cholvin T, Loureiro M, Cassel R, Cosquer B, Geiger K, De Sa Nogueira D, Raingard H, Robelin L, Kelche C, Pereira de Vasconcelos A, Cassel JC (2013) The ventral midline thalamus contributes to strategy shifting in a memory task requiring both prefrontal cortical and hippocampal functions. J Neurosci 33:8772-8783.

Cholvin T, Hok V, Giorgi L, Chaillan FA, Poucet B (2018) Ventral midline thalamus is necessary for hippocampal place field stability and cell firing modulation. J Neurosci 38:158-172.

Cohen NJ, Poldrack RA, Eichenbaum H (1997) Memory for items and memory for relations in the procedural/declarative memory framework. Memory 5:131-178.

Corbit LH, Balleine BW (2000) The role of the hippocampus in instrumental conditioning. J Neurosci 20:4233-4239.

Davis KE, Eacott MJ, Easton A, Gigg J (2013) Episodic-like memory is sensitive to both Alzheimer's-like pathological accumulation and normal ageing processes in mice. Behav Brain Res 254:73-82.

Dere E, Huston JP, De Souza Silva MA (2005) Episodic-like memory in mice: simultaneous assessment of object, place and temporal order memory. Brain Res Brain Res Protoc 16:10-19.

Dolleman-van der Weel MJ, Lopes da Silva FH, Witter MP (2017) Interaction of nucleus reuniens and entorhinal cortex projections in hippocampal field CA1 of the rat. Brain Struct Funct 222:2421-2438.

Duan AR, Varela C, Zhang Y, Shen Y, Xiong L, Wilson MA, Lisman J (2015) Delta frequency optogenetic stimulation of the thalamic nucleus reuniens is sufficient to produce working memory deficits: relevance to schizophrenia. Biol Psychiatry 77:1098-1107.

Hallock HL, Wang A, Shaw CL, Griffin AL (2013) Transient inactivation of the thalamic nucleus reuniens and rhomboid nucleus produces deficits of a working-memory dependent tactile-visual conditional discrimination task. Behav Neurosci 127:860-866.

Hallock HL, Wang A, Griffin AL (2016) Ventral midline thalamus is critical for hippocampal-prefrontal synchrony and spatial working memory. J Neurosci 36:8372-8389.
Henriksen EJ, Colgin LL, Barnes CA, Witter MP, Moser MB, Moser EI (2010) Spatial representation along the proximodistal axis of CA1. Neuron 68:127-137.

Ito HT, Schuman EM (2012) Functional division of hippocampal area CA1 via modulatory gating of entorhinal cortical inputs. Hippocampus 22:372-387.

Ito HT, Zhang SJ, Witter MP, Moser EI, Moser MB (2015) A prefrontalthalamo-hippocampal circuit for goal-directed spatial navigation. Nature 522:50-55.

Jankowski MM, Islam MN, Wright NF, Vann SD, Erichsen JT, Aggleton JP, O'Mara SM (2014) Nucleus reuniens of the thalamus contains head direction cells. Elife 3 .

Jung D, Hwang YJ, Ryu H, Kano M, Sakimura K, Cho J (2016) Conditional knockout of Cav2.1 disrupts the accuracy of spatial recognition of CA1 place cells and Spatial/Contextual recognition behavior. Front Behav Neurosci 10:214.

Karlsson MP, Frank LM (2008) Network dynamics underlying the formation of sparse, informative representations in the hippocampus. J Neurosci 28:14271-14281.

Kim EJ, Kim ES, Park M, Cho J, Kim JJ (2012) Amygdalar stimulation produces alterations on firing properties of hippocampal place cells. J Neurosci 32:11424-11434.

Kim JJ, Lee HJ, Welday AC, Song E, Cho J, Sharp PE, Jung MW, Blair HT (2007) Stress-induced alterations in hippocampal plasticity, place cells, and spatial memory. Proc Natl Acad Sci U S A 104:1829718302.

Knierim JJ (2002) Dynamic interactions between local surface cues, distal landmarks, and intrinsic circuitry in hippocampal place cells. J Neurosci 22:6254-6264.

Knierim JJ, Hamilton DA (2011) Framing spatial cognition: neural representations of proximal and distal frames of reference and their roles in navigation. Physiol Rev 91:1245-1279.

Knierim JJ, Neunuebel JP, Deshmukh SS (2014) Functional correlates of the lateral and medial entorhinal cortex: objects, path integration and local-global reference frames. Philos Trans R Soc Lond B Biol Sci 369:20130369.

Koob GF, Everitt BJ, Robbins TW (2013) Reward, motivation, and addiction. In: Fundamental neuroscience, Ed 4 Squire LR, Berg D, Bloom FE, du Lac S, Ghosh A, Spitzer NC, eds), pp 871-898. San Diego: Academic.

Langston RF, Wood ER (2010) Associative recognition and the hippocampus: differential effects of hippocampal lesions on object-place, object-context and object-place-context memory. Hippocampus 20: $1139-1153$

Larkin MC, Lykken C, Tye LD, Wickelgren JG, Frank LM (2014) Hippocampal output area CA1 broadcasts a generalized novelty signal during an object-place recognition task. Hippocampus 24:773-783.

Lee I, Rao G, Knierim JJ (2004) A double dissociation between hippocampal subfields: differential time course of CA3 and CA1 place cells for processing changed environments. Neuron 42:803-815

Muller RU, Kubie JL (1987) The effects of changes in the environment on the spatial firing of hippocampal complex-spike cells. J Neurosci 7:19511968.

Murai T, Okuda S, Tanaka T, Ohta H (2007) Characteristics of object location memory in mice: behavioral and pharmacological studies. Physiol Behav 90:116-124.

Nakazawa Y, Pevzner A, Tanaka KZ, Wiltgen BJ (2016) Memory retrieval along the proximodistal axis of CA1. Hippocampus 26:1140-1148.

Neunuebel JP, Yoganarasimha D, Rao G, Knierim JJ (2013) Conflicts between local and global spatial frameworks dissociate neural representations of the lateral and medial entorhinal cortex. J Neurosci 33: 9246-9258.

O'Keefe J (1979) A review of the hippocampal place cells. Prog Neurobiol 13:419-439.

Park M, Kim CH, Jo S, Kim EJ, Rhim H, Lee CJ, Kim JJ, Cho J (2015) Chronic stress alters spatial representation and bursting patterns of place cells in behaving mice. Sci Rep 5:16235.

Park SB, Lee I (2016) Increased variability and asymmetric expansion of the hippocampal spatial representation in a distal cue-dependent memory task. Hippocampus 26:1033-1050. 
Paxinos G, Franklin KB (2004) The mouse brain in stereotaxic coordinates. Houston, Texas: Gulf Professional Publishing.

Renaudineau S, Poucet B, Save E (2007) Flexible use of proximal objects and distal cues by hippocampal place cells. Hippocampus 17:381-395.

Salay LD, Ishiko N, Huberman AD (2018) A midline thalamic circuit determines reactions to visual threat. Nature 557:183-189.

Scoville WB, Milner B (1957) Loss of recent memory after bilateral hippocampal lesions. J Neurol Neurosurg Psychiatry 20:11-21.

Van der Werf YD, Witter MP, Groenewegen HJ (2002) The intralaminar and midline nuclei of the thalamus: anatomical and functional evidence for participation in processes of arousal and awareness. Brain Res Rev 39:107-140.

Vertes RP, Hoover WB, Do Valle AC, Sherman A, Rodriguez JJ (2006) Ef- ferent projections of reuniens and rhomboid nuclei of the thalamus in the rat. J Comp Neurol 499:768-796.

Vertes RP, Hoover WB, Szigeti-Buck K, Leranth C (2007) Nucleus reuniens of the midline thalamus: link between the medial prefrontal cortex and the hippocampus. Brain Res Bull 71:601-609.

Vertes RP, Linley SB, Hoover WB (2015) Limbic circuitry of the midline thalamus. Neurosci Biobehav Rev 54:89-107.

Xu W, Südhof TC (2013) A neural circuit for memory specificity and generalization. Science 339:1290-1295.

Yoganarasimha D, Yu X, Knierim JJ (2006) Head direction cell representations maintain internal coherence during conflicting proximal and distal cue rotations: comparison with hippocampal place cells. J Neurosci 26: $622-631$. 